\title{
Using the Singly Deprotonated Triethanolamine to Prepare Dinuclear Lanthanide(III) Complexes: Synthesis, Structural Characterization and Magnetic Studies ${ }^{\dagger}$
}

\author{
Ioannis Mylonas-Margaritis ${ }^{1}$, Julia Mayans ${ }^{2}$, Stavroula-Melina Sakellakou ${ }^{1}$, \\ Catherine P. Raptopoulou ${ }^{3}$, Vassilis Psycharis ${ }^{3}$, Albert Escuer ${ }^{2, *}$ and Spyros P. Perlepes ${ }^{1,4, *}$ \\ 1 Department of Chemistry, University of Patras, 26504 Patras, Greece; \\ ioannismylonasmargaritis@gmail.com (I.M.-M.), melinasakell@gmail.com (S.-M.S.) \\ 2 Departament de Química Inorgànica i Orgànica, Secció Inorgànica, and Institue of Nanoscience and \\ Nanotechnology (IN2UB), Universitat de Barcelona, Av. Diagonal 645, 08028 Barcelona, Spain; \\ julia.mayans@qi.ub.edu \\ 3 Institute of Nanoscience and Nanotechnology, NCSR “Demokritos", 15310 Aghia Paraskevi Attikis, Greece; \\ c.raptopoulou@inn.demokritos.gr (C.P.R.); v.psycharis@inn.demokritos.gr (V.P.) \\ 4 Institute of Chemical Engineering Sciences, Foundation for Research and Technology-Hellas (FORTH/ICE-HT), \\ Platani, P.O. Box 1414, 26504 Patras, Greece \\ * Correspondence: albert.escuer@ub.edu (A.E.); perlepes@patreas.upatras.gr (S.P.P.); \\ Tel.: +34-93-403-9141 (A.E.); +30-2610-996-730 (S.P.P.) \\ + This article is dedicated to Dante Gatteschi, a pioneer in the interdisciplinary field of Molecular Magnetism \\ and a great mentor, on the occasion of his 70th birthday.
}

Academic Editor: Kevin Bernot

Received: 21 December 2016; Accepted: 16 January 2017; Published: 26 January 2017

Abstract: The 1:1 reactions between hydrated lanthanide(III) nitrates and triethanolamine $\left(\mathrm{teaH}_{3}\right)$ in $\mathrm{MeOH}$, in the absence of external bases, have provided access to the dinuclear complexes $\left[\mathrm{Ln}_{2}\left(\mathrm{NO}_{3}\right)_{4}\left(\mathrm{teaH}_{2}\right)_{2}\right](\mathrm{Ln}=\mathrm{Pr}, \mathbf{1} ; \mathrm{Ln}=\mathrm{Gd}, \mathbf{2} ; \mathrm{Ln}=\mathrm{Tb}, 3 ; \mathrm{Ln}=\mathrm{Dy}, 4 ; \mathrm{Ln}=\mathrm{Ho}, 5)$ containing the singly deprotonated form of the ligand. Use of excess of the ligand in the same solvent gives mononuclear complexes containing the neutral ligand and the representative compound $\left[\mathrm{Pr}\left(\mathrm{NO}_{3}\right)\left(\operatorname{teaH}_{3}\right)_{2}\right]\left(\mathrm{NO}_{3}\right)_{2}$ (6) was characterized. The structures of the isomorphous complexes $1 \cdot 2 \mathrm{MeOH}, 2 \cdot 2 \mathrm{MeOH}$ and $4 \cdot 2 \mathrm{MeOH}$ were solved by single-crystal X-ray crystallography; the other two dinuclear complexes are proposed to be isostructural with 1, 2 and 4 based on elemental analyses, IR spectra and powder XRD patterns. The IR spectra of 1-6 are discussed in terms of structural features of the complexes. The two $\mathrm{Ln}^{\mathrm{III}}$ atoms in centrosymmetric $1 \cdot 2 \mathrm{MeOH}, 2 \cdot 2 \mathrm{MeOH}$ and $4 \cdot 2 \mathrm{MeOH}$ are doubly bridged by

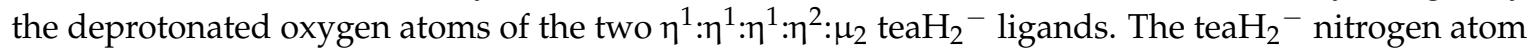
and six terminal oxygen atoms (two from the neutral hydroxyl groups of tea $\mathrm{H}_{2}{ }^{-}$and four from two slightly anisobidentate chelating nitrato groups) complete 9-coordination at each $4 \mathrm{f}$-metal center. The coordination geometries of the metal ions are spherical-relaxed capped cubic $(1 \cdot 2 \mathrm{MeOH})$, Johnson tricapped trigonal prismatic $(2 \cdot 2 \mathrm{MeOH})$ and spherical capped square antiprismatic $(4 \cdot 2 \mathrm{MeOH})$. $\mathrm{O}-\mathrm{H} \cdots \mathrm{O} \mathrm{H}$ bonds create chains parallel to the $a$ axis. The cation of 6 has crystallographic two fold symmetry and the rotation axis passes through the $\mathrm{Pr}{ }^{\mathrm{III}}$ atom, the nitrogen atom of the coordinated nitrato group and the non-coordinated oxygen atom of the nitrato ligand. The metal ion is bound to the two $\eta^{1}: \eta^{1}: \eta^{1}: \eta^{1}$ teaH $H_{3}$ ligands and to one bidentate chelating nitrato group. The 10-coordinate $\mathrm{Pr}^{\mathrm{III}}$ atom has a sphenocoronal coordination geometry. Several $\mathrm{H}$ bonds are responsible for the formation of a 3D architecture in the crystal structure of $\mathbf{6}$. Complexes 1-6 are new members of a small family of homometallic $\mathrm{Ln}^{\mathrm{III}}$ complexes containing various forms of triethanolamine as ligands. Dc magnetic susceptibility studies in the $2-300 \mathrm{~K}$ range reveal the presence of a weak to moderate intramolecular antiferromagnetic exchange interaction $\left(J=-0.30(2) \mathrm{cm}^{-1}\right.$ based on the spin Hamiltonian $\left.\hat{H}=-J\left(\hat{S}_{\mathrm{Gd} 1} \cdot \hat{S}_{\mathrm{Gd} 1} /\right)\right)$ for $\mathbf{2}$ and probably weak antiferromagnetic exchange interactions 
within the molecules of 3-5. The antiferromagnetic $\mathrm{Gd}^{\mathrm{III}} \ldots \mathrm{Gd} \mathrm{III}^{\mathrm{II}}$ interaction in $\mathbf{2}$ is discussed in terms of known magnetostructural correlations for complexes possessing the $\left\{\mathrm{Gd}_{2}\left(\mu_{2}-\mathrm{OR}\right)_{2}\right\}^{4+}$ core. Ac magnetic susceptibility measurements in zero dc field for 3-5 do not show frequency dependent out-of-phase signals; this experimental fact is discussed and rationalized for complex 4 in terms of the magnetic anisotropy axis for each Dy ${ }^{\mathrm{III}}$ center and the oblate electron density of the metal ion.

Keywords: dinuclear lanthanide(III) complexes; ground state magnetic axes of dysprosium(III) ions in a complex; magnetic properties; triethanolamine-lanthanide(III) complexes

\section{Introduction}

Electrons residing in $4 \mathrm{f}$ orbitals give trivalent lanthanides $\left(\mathrm{Ln}^{\mathrm{III}}\right)$ interesting (and sometimes difficult to understand in detail) optical and magnetic properties that are currently exploited in modern technology. As far as magnetism is concerned, $\mathrm{Ln}^{\mathrm{III}}$ ions have been the key components of hard permanent magnets, such as the SmCo and FeNdB magnets, as well as the platform to investigate interesting physical phenomena, e.g., the spin-ice behavior in $\mathrm{Dy}_{2} \mathrm{Ti}_{2} \mathrm{O}_{7}$ [1]. $\mathrm{Ln}{ }^{\mathrm{III}}$ complexes have also attracted intense interest since the first days of Molecular Magnetism, because of their high magnetic moments and large anisotropies [2]. However, it was after the discovery that magnetic anisotropy could lead to magnetic hysteresis at the molecular level in a class of compounds known as Single-Molecule Magnets (SMMs) [3,4] that an explosion in their study has occurred. In 2003, Ishikawa's group reported SMM behavior in the double-decker phthalocyanine complexes $\left(\mathrm{Bu}^{n}{ }_{4} \mathrm{~N}\right)\left[\operatorname{Ln}(\mathrm{pc})_{2}\right](\mathrm{Ln}=\mathrm{Tb}, \mathrm{Dy})$ [5], which gave birth of the $\mathrm{Ln}^{\mathrm{III}}$ SMM era [6,7]. The magnetization dynamics of dinuclear and polynuclear $\mathrm{Ln}^{\mathrm{III}}$ SMMs mainly originate from single-ion behavior because it is difficult to create effective pathways for magnetic interactions between metal centers due to the nature of inner $4 \mathrm{f}$ electrons; in general, both the exchange and dipolar interactions between $\mathrm{Ln}^{\mathrm{III}}$ ions are weak [8]. This situation is different from the magnetic relaxation of transition-metal-based SMMs, in which both the spin and exchange interactions contribute simultaneously to the magnetization dynamics [3]. As an alternative candidate, $\mathrm{Ln}^{\mathrm{III}}$ centers that are usually weakly coupled in dinuclear and polynuclear complexes have shown advantages with respect to SMM studies because large magnetization reversal energy barriers can be achieved via single-ion anisotropy originating from strong spin-orbit coupling and crystal field effects $[6,8,9]$.

Dinuclear complexes represent the simplest molecular entities which allow the study of magnetic interactions between $\mathrm{Ln}^{\mathrm{III}}$ spin carriers [10]. By studying such systems, researchers could expect to understand the nature and strength of $\mathrm{Ln}^{\mathrm{IIII}} \ldots \mathrm{Ln}{ }^{\mathrm{III}}$ exchange interactions, as well as possible alignment of spin vectors and anisotropy axes. These parameters can be affected by the molecular symmetry, the coordination geometry and/or the bridging ligands, which may act as superexchange pathways. More importantly, dinuclear $\mathrm{Ln}{ }^{\mathrm{III}}$ SMMs are very important model systems to answer basic questions regarding single-ion relaxation vs. slow magnetic relaxation arising from the molecule as an entity. Thus, $\mathrm{Ln}_{2}$ III complexes are highly desirable [10-20]. Another interesting area to which dinuclear lanthanide(III) complexes (and also mononuclear ones) are relevant is quantum computation; $\mathrm{Ln}^{\mathrm{III}}$ ions are promising candidates for encoding quantum information [21,22]. For the realization of a quantum gate, asymmetric dinuclear molecules composed of two weakly coupled $\mathrm{Ln}^{\mathrm{III}}$ qubits are promising [21]. However, the synthesis of asymmetric molecular dimers is not straightforward, as nature tends to make them symmetric. From the synthetic inorganic chemistry viewpoint, the most logical simple route for the isolation of dinuclear $4 \mathrm{f}$-metal ion complexes is the simultaneous employment of bidentate bridging anionic groups (e.g., $\eta^{1}: \eta^{1}: \mu_{2}$ and $/$ or $\eta^{1}: \eta^{2}: \mu_{2}$ carboxylate groups) and chelating (most often bidentate or tridentate, e.g. bpy, phen, terpy, etc.) neutral capping organic ligands, which terminate oligomerization or polymerization by blocking two or three coordination sites per $\mathrm{Ln}^{\mathrm{III}}$ center [23]. Another method is the simultaneous employment of capping bidentate nitrato groups (nitrato ligands 
have little tendency for bridging in Ln ${ }^{\mathrm{III}}$ chemistry) and neutral or anionic organic ligands that can, in principle, bridge only two metal centers; in addition to the bridging functionality, the ligands should preferably possess "chelating" parts to satisfy the demand for high coordination numbers at the $\mathrm{Ln}^{\mathrm{III}}$ centers [24-26]. Thus, the choice of the primary organic ligands is crucial for the synthesis of $\mathrm{Ln}_{2}$ III complexes.

With all the above in mind and given the recently initiated interest of our groups in $\mathrm{Ln}_{2}{ }_{2}$ complexes with interesting magnetic and/or luminescence properties [23,25-27], we report here the synthesis, structures and magnetic properties of new such complexes bearing the monoanion of tris(2-hydroxyethyl)amine (the empirical name is triethanolamine, abbreviated hereafter as tea $\mathrm{H}_{3}$, Scheme 1). This ligand is very popular in $3 \mathrm{~d}-$ and mixed $3 \mathrm{~d} / 4 \mathrm{f}-$ metal cluster chemistry (representative 3d/4f-metal compounds based on anionic forms of teaH $\mathrm{H}_{3}$ are described in refs [28-31]), but with limited used in homometallic $\mathrm{Ln}^{\mathrm{III}}$ and $\mathrm{Ln}^{\mathrm{II}}\left(\mathrm{Ln}^{\mathrm{II}}=\mathrm{Eu}^{\mathrm{II}}, \mathrm{Yb}^{\mathrm{II}}\right)$ chemistry. $\mathrm{Ln}^{\mathrm{III}}$ and $\mathrm{Ln}^{\mathrm{II}}$ complexes containing only the neutral ligand are always mononuclear [32-36], whereas the doubly deprotonated form (teaH ${ }^{-}$) of the ligand, either alone or with the simultaneous presence of other bridging inorganic or organic ligands, have led to high nuclearity $\mathrm{Ln}^{\mathrm{III}}$ clusters [37-39]. The singly deprotonated $\left(\mathrm{teaH}_{2}{ }^{-}\right.$) ligand has been employed only with combination with other bridging groups and such ligand "blends" give polynuclear $\mathrm{Ln}^{\mathrm{III}}$ complexes [38-40], although the teaH ${ }_{2}{ }^{-}$group usually (but not always) bridges two metal centers.
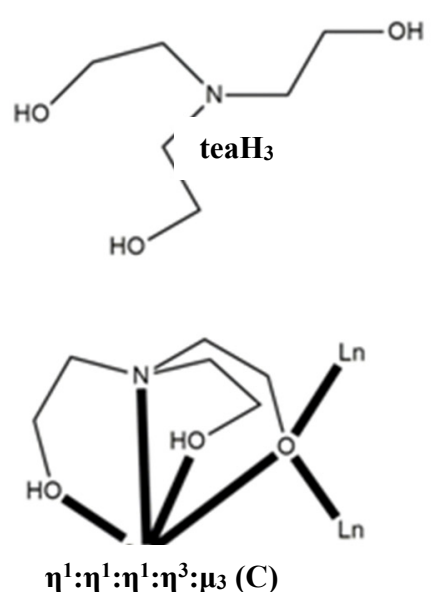

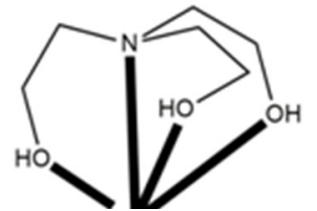

$\eta^{1}: \eta^{1}: \eta^{1}: \eta^{1}(\mathrm{~A})$

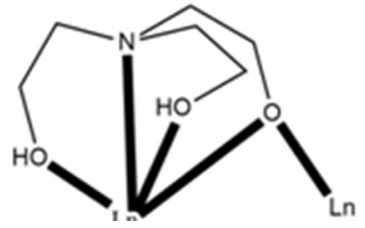

$\eta^{1}: \eta^{1}: \eta^{1}: \eta^{2}: \mu_{2}(B)$

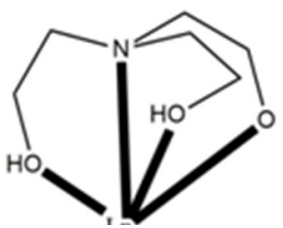

$\eta^{1}: \eta^{1}: \eta^{1}: \eta^{1}(D)$

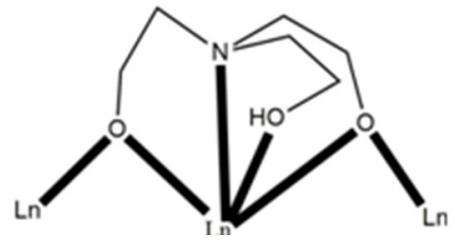

$\eta^{1}: \eta^{1}: \eta^{2}: \eta^{2}: \mu_{3}(E)$
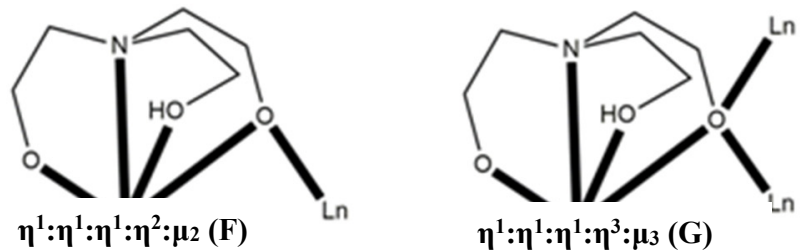

$\eta^{1}: \eta^{1}: \eta^{1}: \eta^{3}: \mu_{3}(G)$

Scheme 1. The structural formula of teaH $\mathrm{H}_{3}$ (up, left) and the to date crystallographically established coordination modes of the: neutral (A); and monoanionic (B-D) teaH ${ }_{2}^{-}$; and dianionic (E-G) teaH ${ }^{2-}$ ligands in homometallic $\mathrm{Ln}^{\mathrm{II}}(\mathrm{Ln}=\mathrm{Eu}, \mathrm{Yb})$ and $\mathrm{Ln}^{\mathrm{III}}$ chemistry.

\section{Results and Discussion}

\subsection{Synthetic Comments and IR Discussion}

Since we were interested in isolating dinuclear lanthanide(III) complexes with the singly deprotonated form of triethanolamine, i.e., teaH ${ }_{2}{ }^{-}$, as ligand, we avoided the addition of external bases $\left(\mathrm{Et}_{3} \mathrm{~N}, \mathrm{LiOH}, \mathrm{Me}_{4} \mathrm{NOH}\right.$, etc.) in the systems. Previous reports have shown that use of $\mathrm{Et}_{3} \mathrm{~N}$ in the $\mathrm{Ln}^{\mathrm{III}} /$ teaH 3 reaction mixtures in $\mathrm{MeOH}$ and $\mathrm{MeOH} / \mathrm{CH}_{2} \mathrm{Cl}_{2}$ lead to clusters $\left[\mathrm{Ln}_{6}\left(\mathrm{NO}_{3}\right)_{6}(\text { teaH })_{6}\right]$ [37] 
and $\left[\mathrm{Ln}_{8}(\mathrm{OH})_{6}(\text { teaH })_{6}\left(\text { teaH }_{2}\right)_{2}\left(\text { teaH }_{3}\right)_{2}\right]\left(\mathrm{O}_{3} \mathrm{SCF}_{3}\right)_{4}[39]$, respectively, containing exclusively or partially the dianionic teaH ${ }^{2-}$ ligand. We hoped that the formation of $\mathrm{Ln}^{\mathrm{III}}-\mathrm{O}\left(\mathrm{teaH}_{3}\right)$ bonds in solution would lead to moderate polarization of the $-\mathrm{CH}_{2}-\mathrm{CH}_{2}-\mathrm{O}-\mathrm{H}$ groups of teaH $\mathrm{H}_{3}$ and subsequent single deprotonation of the ligand; this has, indeed, turned out to be the case. Thus, the 1:1 $\mathrm{Ln}\left(\mathrm{NO}_{3}\right)_{3} \cdot x \mathrm{H}_{2} \mathrm{O} /$ teaH $\mathrm{H}_{3}$ reaction mixtures in $\mathrm{MeOH}$ gave solutions from which were subsequently isolated crystals of the dinuclear complexes $\left[\mathrm{Ln}_{2}\left(\mathrm{NO}_{3}\right)_{4}(\mathrm{teaH})_{2}\right](\mathrm{Ln}=\mathrm{Pr}, \mathbf{1} ; \mathrm{Ln}=\mathrm{Gd}, \mathbf{2} ; \mathrm{Ln}=\mathrm{Tb}, \mathbf{3}$; $\mathrm{Ln}=\mathrm{Dy}, 4 ; \mathrm{Ln}=\mathrm{Ho}, 5$ ) in yields of ca. 50\%. The crystals of 1,2 and 4 (in the form of their bis-methanol solvates) were of X-ray quality and their structures were solved by single crystal X-ray crystallography. Complexes $\mathbf{3}$ and $\mathbf{5}$ (isolated as polycrystalline powders) are proposed to be isostructural with 1, 2 and 4 based on elemental analyses and IR spectra (vide supra), as well as on powder XRD patterns (vide infra, Figure S1) for 2, 3 and 4. Assuming that the dinuclear complexes are the only products from the general $\mathrm{Ln}\left(\mathrm{NO}_{3}\right)_{3} \cdot x \mathrm{H}_{2} \mathrm{O} /$ teaH 3 (1:1) reaction system in $\mathrm{MeOH}$, their formation can by summarized by Equation (1), where $x$ is 6 or 5 :

$$
\begin{aligned}
& 2 \mathrm{Ln}\left(\mathrm{NO}_{3}\right)_{3} \cdot x \mathrm{H}_{2} \mathrm{O}+2 \text { tea } \quad \mathrm{H}_{3} \stackrel{\mathrm{MeOH}}{\longrightarrow} \\
& {\left[\mathrm{Ln}_{2}\left(\mathrm{NO}_{3}\right)_{4}(\text { teaH })_{2}\right]+2 \mathrm{H}^{+}+2 \mathrm{NO}_{3}^{-}+2 x \mathrm{H}_{2} \mathrm{O}} \\
& \text { 1-5 }
\end{aligned}
$$

Analogous reactions in $\mathrm{MeCN}$ gave amorphous powders which we could not characterize.

In a next step, we examined the influence of the teaH $\mathrm{H}_{3}: \mathrm{Ln}^{\mathrm{III}}$ reaction ratio on the product identity. Using an excess of the ligand, i.e., teaH $\mathrm{H}_{3}: \mathrm{Ln}\left(\mathrm{NO}_{3}\right)_{3} \cdot x \mathrm{H}_{2} \mathrm{O}$ molar ratios of 2.5:1, we anticipated the formation of complexes of the general formula $\left[\mathrm{Ln}_{2}\left(\mathrm{NO}_{3}\right)_{2}\left(\mathrm{teaH}_{2}\right)_{4}\right]$. Somewhat to our disappointment, the products of such reactions in $\mathrm{MeOH}$ with the lighter lanthanides are the mononuclear complexes $\left[\mathrm{Ln}\left(\mathrm{NO}_{3}\right)\left(\mathrm{teaH}_{3}\right)_{2}\right]\left(\mathrm{NO}_{3}\right)_{2}$, suggesting that the excess of teaH $\mathrm{H}_{3}$ does not favor the efficient polarization (due to coordination) of the $-\mathrm{CH}_{2}-\mathrm{CH}_{2}-\mathrm{O}-\mathrm{H}$ groups of the ligand that would lead to its single deprotonation. To fully characterize the mononuclear complexes, we have crystallized the representative $\mathrm{Pr}^{\mathrm{III}}$ complex and solved its structure (vide infra); its formation is summarized by Equation (2):

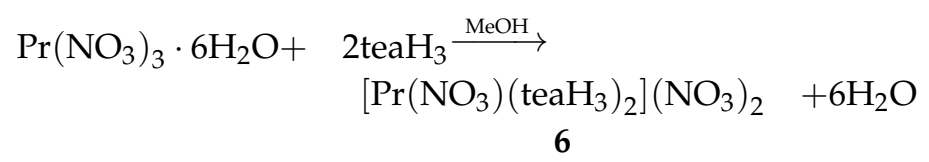

IR evidence shows that the mononuclear complexes with the heavier lanthanide(III) ions, e.g., Dy ${ }^{\mathrm{III}}, \mathrm{Ho}{ }^{\mathrm{III}}$ and $\mathrm{Er}{ }^{\mathrm{III}}$, are probably best formulated as eight-coordinate $\left.\left[\mathrm{Ln}(\mathrm{teaH})_{2}\right)_{2}\right]\left(\mathrm{NO}_{3}\right)_{3}$ as a consequence of the lanthanide contraction. Since we were not particularly interested in mononuclear $\mathrm{Ln}^{\mathrm{III}} / \mathrm{teaH}_{3}$ complexes, we did not pursue this chemistry further.

In the IR spectra of well-dried samples of complexes 1-5, the strong intensity broad band at $\sim 3350 \mathrm{~cm}^{-1}$ is assigned to the $v(\mathrm{OH})$ vibration of the coordinated $-\mathrm{OH}$ groups of tea $\mathrm{H}_{2}{ }^{-}$; this mode in the spectrum of 6 appears as two bands at $\sim 3400$ and $3230 \mathrm{~cm}^{-1}$ [41]. The broadness of the bands is indicative of the participation of the hydroxyl groups in H-bonding. The bands at 1650 and $1473-1458 \mathrm{~cm}^{-1}$ are tentatively assigned to the $\delta(\mathrm{OH})$ and $v(\mathrm{C}-\mathrm{C})$ modes, respectively. The $\mathrm{KBr}$ IR spectra of 1-5 exhibit a strong band at $1384 \mathrm{~cm}^{-1}$, characteristic of the $v_{3}\left(E^{\prime}\right)\left[v_{\mathrm{d}}(\mathrm{N}-\mathrm{O})\right]$ mode of the planar $D_{3 \mathrm{~h}}$ ionic nitrate [42,43]; such a nitrate is absent in the complexes. The appearance of this band suggests that the nitrato ligands are replaced by bromides that are present in excess in the spectroscopic $\mathrm{KBr}$ matrix, thus producing ionic nitrates $\left(\mathrm{KNO}_{3}\right)$; this replacement is facilitated by the pressure used for the preparation of the pellet [42,43]. In accordance with this conclusion, the band at $1384 \mathrm{~cm}^{-1}$ is absent from the mull spectra of these complexes. The mull IR bands at $\sim 1480$ and $\sim 1290 \mathrm{~cm}^{-1}$ in $\mathbf{1 - 5}$ are assigned [25] to the $v_{1}\left(A_{1}\right)[v(\mathrm{~N}=\mathrm{O})]$ and $v_{5}$ (Btextsubscript2) $\left[v_{\text {as }}\left(\mathrm{NO}_{2}\right)\right]$ vibrational modes, respectively, of the bidentate chelating $\left(C_{2 \mathrm{v}}\right)$ nitrato group. The separation of these two highest-wavenumber stretching bands $\left(\sim 190 \mathrm{~cm}^{-1}\right)$ is large and typical of bidentate nitrates [25,42,43]. The KBr IR spectrum 
of 6 (which contains both chelating and ionic nitrates) exhibits only the ionic nitrate $\left(D_{3 \mathrm{~h}}\right)$ band at $1383 \mathrm{~cm}^{-1}$ due to the bidentate nitrato group $\rightarrow$ ionic nitrate transformation mentioned above; however, the mull spectra (nujol and hexachlorobutadiene) show the typical bands of both the bidentate nitrato group (at 1490 and $1285 \mathrm{~cm}^{-1}$ ) and ionic nitrate $\left(1383 \mathrm{~cm}^{-1}\right)$, as expected. The IR spectra (KBr) of the representative dinuclear complex 3 and the free teaH $\mathrm{H}_{3}$ ligand (liquid between CsI plates) are presented in Figures S2 and S3, respectively.

\subsection{Description of Structures}

The structures of $1 \cdot 2 \mathrm{MeOH}, 2 \cdot 2 \mathrm{MeOH}, 4 \cdot 2 \mathrm{MeOH}$ and 6 have been solved by single-crystal X-ray crystallography (Table 1). Complexes $1 \cdot 2 \mathrm{MeOH}, 2 \cdot 2 \mathrm{MeOH}$ and $4 \cdot 2 \mathrm{MeOH}$ are isomorphous and thus only the structure of $4 \cdot 2 \mathrm{MeOH}$ will be described in detail. Complexes 3 and 5 are proposed to have similar structures with those of $\mathbf{1}, \mathbf{2}$ and $\mathbf{4}$ based on elemental analyses, IR spectra and powder X-ray patterns (Figure 1 and Figure S1). The measured pXRD patterns of 2, 3 and 4 are very similar indicating that the complexes are isostructural. The differences in intensity may be due to the preferred orientation of the crystalline powder samples $[44,45]$. The experimental patterns agree satisfactorily with those calculated from the single-crystal X-ray diffraction data. However, they are not identical; a possible reason for this is the fact that the measured patterns correspond to unsolvated complexes, i.e., 2, 3 and 4 (this is also confirmed by elemental analyses), while the simulated ones refer to the bis(methanol) solvates. Structural plots of the compounds $4 \cdot 2 \mathrm{MeOH}$ and 6 , as well as supramolecular features of complex 4.2MeOH, are presented in Figures 2-4, while numerical data are listed in Tables 2 and 3 and Tables S1-S6. Structural plots of $\mathbf{1} \cdot 2 \mathrm{MeOH}$ and $\mathbf{2} \cdot 2 \mathrm{MeOH}$ are shown in Figures $\mathrm{S} 4$ and S5, respectively.

Table 1. Crystallographic data for complexes $1 \cdot 2 \mathrm{MeOH}, 2 \cdot 2 \mathrm{MeOH}, 4 \cdot 2 \mathrm{MeOH}$ and 6.

\begin{tabular}{|c|c|c|c|c|}
\hline Parameter & $1 \cdot 2 \mathrm{MeOH}$ & $2 \cdot 2 \mathrm{MeOH}$ & $4 \cdot 2 \mathrm{MeOH}$ & 6 \\
\hline Formula & $\mathrm{C}_{14} \mathrm{H}_{36} \mathrm{~N}_{6} \operatorname{Pr}_{2} \mathrm{O}_{20}$ & $\mathrm{C}_{14} \mathrm{H}_{36} \mathrm{~N}_{6} \mathrm{Gd}_{2} \mathrm{O}_{20}$ & $\mathrm{C}_{14} \mathrm{H}_{36} \mathrm{~N}_{6} \mathrm{Dy}_{2} \mathrm{O}_{20}$ & $\mathrm{C}_{12} \mathrm{H}_{30} \mathrm{~N}_{5} \mathrm{PrO}_{15}$ \\
\hline Formula weight & 890.31 & 922.99 & 933.49 & 652.32 \\
\hline Crystal system & triclinic & triclinic & triclinic & monoclinic \\
\hline Space group & $P \overline{1}$ & $P \overline{1}$ & $P \overline{1}$ & $C 2 / c$ \\
\hline Radiation & Mo K $\alpha$ & Mo K $\alpha$ & Mo K $\alpha$ & Mo K $\alpha$ \\
\hline$T / K$ & 160 & 230 & 160 & 160 \\
\hline$a / \AA$ & $8.3271(2)$ & $8.3299(4)$ & $8.2897(4)$ & $11.5500(2)$ \\
\hline$b / \AA$ & $8.6978(2)$ & $8.6424(4)$ & $8.6055(4)$ & $14.8428(3)$ \\
\hline$c / \AA$ & $10.3787(3)$ & $10.3733(5)$ & $10.2855(5)$ & $13.8550(3)$ \\
\hline$\alpha /{ }^{\circ}$ & $86.893(1)$ & $86.964(2)$ & $86.892(1)$ & 90 \\
\hline$\beta /{ }^{\circ}$ & $80.373(1)$ & $79.310(1)$ & $79.141(1)$ & $107.393(1)$ \\
\hline$\gamma /{ }^{\circ}$ & $84.632(1)$ & $84.494(2)$ & $84.532(1)$ & 90 \\
\hline$V / \AA^{3}$ & $737.30(3)$ & $729.96(6)$ & $716.83(6)$ & $2266.62(8)$ \\
\hline Z & 1 & 1 & 1 & 4 \\
\hline$D_{\text {calc }} / \mathrm{g} \cdot \mathrm{cm}^{-3}$ & 2.005 & 2.100 & 2.162 & 1.832 \\
\hline$\mu / \mathrm{mm}^{-1}$ & 3.36 & 4.60 & 5.27 & 2.23 \\
\hline Reflns measured & 15028 & 13695 & 9845 & 21716 \\
\hline Reflns unique $\left(R_{\text {int }}\right)$ & $3210(0.018)$ & $3184(0.024)$ & $3119(0.026)$ & $2463(0.021)$ \\
\hline Reflns with $\mathrm{I}>2 \sigma(I)$ & 3143 & 3099 & 3042 & 2424 \\
\hline $\mathrm{GOF}$ on $F^{2}$ & 1.12 & 1.07 & 1.07 & 1.08 \\
\hline$R_{1}^{a}[I>2 \sigma(I)]$ & 0.0129 & 0.0129 & 0.0142 & 0.0134 \\
\hline$w R_{2}{ }^{b}$ (all data) & 0.0305 & 0.0292 & 0.0332 & 0.0347 \\
\hline
\end{tabular}

$$
{ }^{\mathrm{a}} R_{1}=\sum\left(\left|F_{o}\right|-\left|F_{c}\right|\right) / \Sigma\left(\left|F_{o}\right|\right) ;{ }^{\mathrm{b}} w R_{2}=\left\{\Sigma\left[w\left(F_{O}^{2}-F_{c}^{2}\right)^{2}\right] / \Sigma\left[w\left(F_{O}^{2}\right)^{2}\right]\right\}^{\frac{1}{2}} .
$$

Complex $4 \cdot 2 \mathrm{MeOH}$ crystallizes in the triclinic space group $P \overline{1}$. Its structure consists of dinuclear $\left[\mathrm{Dy}_{2}\left(\mathrm{NO}_{3}\right)_{4}\left(\text { teaH }{ }_{2}\right)_{2}\right]$ and solvate $\mathrm{MeOH}$ molecules in an 1:2 ratio; the latter will not be further discussed. The asymmetric unit contains half of the dinuclear complex molecule and one $\mathrm{MeOH}$ lattice solvent. The dinuclear molecule possesses an inversion center at the mid-point of the Dy1 $\cdots$ Dy $1^{\prime}$ distance (3.669(1) ^). The two Dy ${ }^{\mathrm{III}}$ atoms are doubly bridged by the deprotonated oxygen atoms 
$\left(\mathrm{O} 1\right.$, and $\left.\mathrm{O} 1^{\prime}\right)$ of the two $\eta^{1}: \eta^{1}: \eta^{1}: \eta^{2}: \mu_{2}$ teaH ${ }_{2}{ }^{-}$ligands (Scheme $\left.1 \mathrm{~B}\right)$. The teaH ${ }_{2}{ }^{-}$nitrogen atom (N1) and six terminal oxygen atoms (two from the neutral hydroxyl groups of the organic ligand and four from two slightly anisobidentate chelating nitrato groups) complete 9-coordination at each metal center. The Dy-O/N bond lengths are typical of nine-coordinate Dy ${ }^{I I I}$ atoms $[27,46]$. The Dy1-O1,O1' bond lengths (2.265(1), and 2.236(1) $\AA$ ) involving the deprotonated oxygen atoms are shorter than the Dy1-O2,O3 bond distances (2.363(1), and 2.466(2) $\AA$ ) involving the neutral hydroxyl atoms of tea $\mathrm{H}_{2}{ }^{-}$, as expected. Due to the bidentate coordination of the nitrato lligands, the N2-O6 (1.233(2) $\AA$ ) and N3-O9 (1.216(2) $\AA$ ) bond distances involving the "free", i.e., uncoordinated, oxygen atoms are shorter than the N2-O4, O5 (1.261(2) $\mathrm{A}$ ) and N3-O7,O8 (1.263(2), and 1.280(2) $\AA$ ) distances involving the coordinated oxygen atoms.

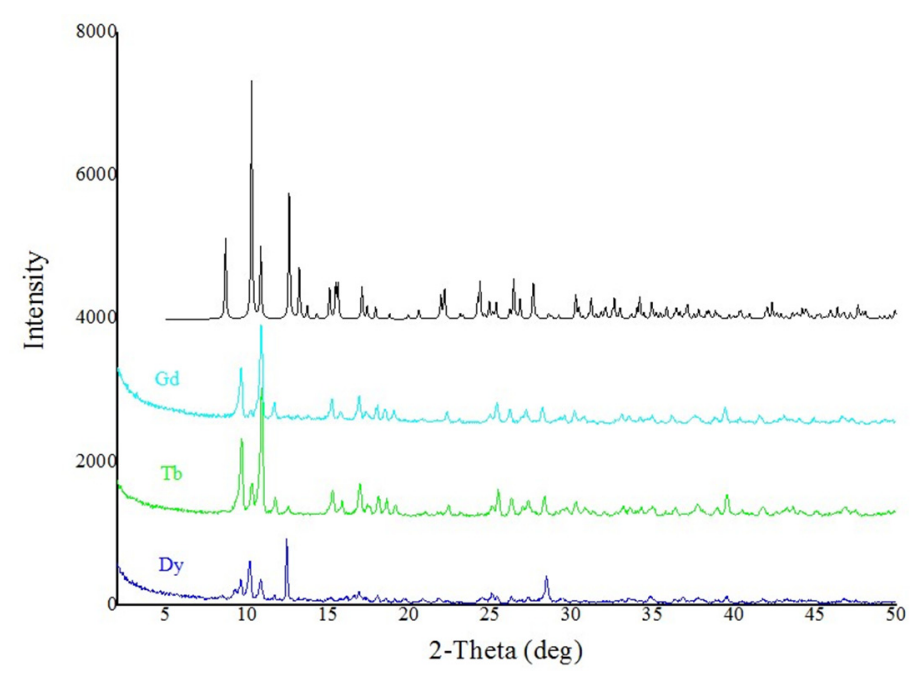

Figure 1. Experimental X-ray diffraction patterns of complexes 2 (cyan), 3 (green) and 4 (blue), and the theoretical pattern for complex 2 (black).

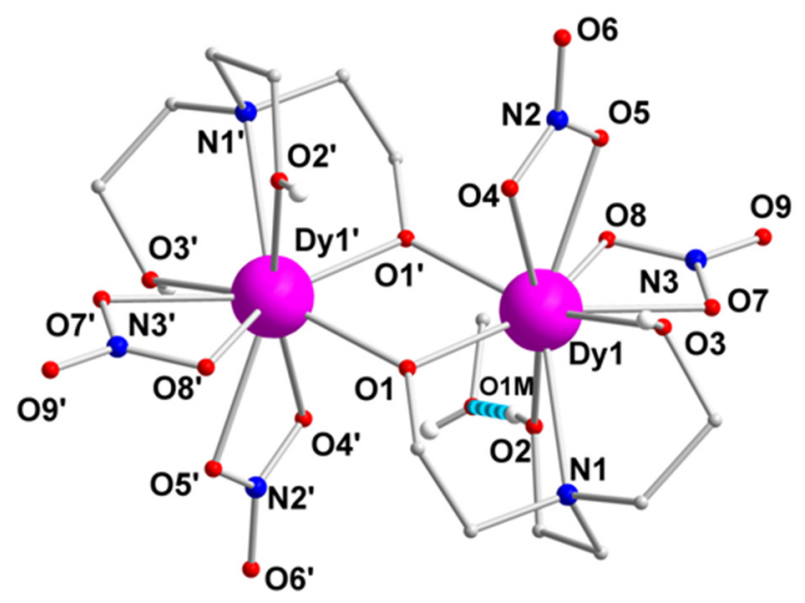

Figure 2. Partially labeled plot of the molecule $\left[\mathrm{Dy}_{2}\left(\mathrm{NO}_{3}\right)_{4}\left(\mathrm{teaH}_{2}\right)_{2}\right]$ that is present in the structure of $4 \cdot 2 \mathrm{MeOH}$. One lattice $\mathrm{MeOH}$ molecule is also shown. The thick dotted cyan line represents the $\mathrm{O} 2-\mathrm{H}(\mathrm{O} 2) \cdots \mathrm{O} 1 \mathrm{M} \mathrm{H}$ bond. Symmetry operation used to generate equivalent atoms: $\left({ }^{\prime}\right)-x+1,-y,-z+1$. Only the $\mathrm{H}$ atoms at $\mathrm{O} 2$ and $\mathrm{O} 3$ (and their centrosymmetric equivalents) are shown. 
Table 2. Selected interatomic distances $(\AA)$ and bond angles $\left(^{\circ}\right)$ for the representative complex $\left[\mathrm{Dy}_{2}\left(\mathrm{NO}_{3}\right)_{4}\left(\mathrm{teaH}_{2}\right)_{2}\right] \cdot 2 \mathrm{MeOH}(4 \cdot 2 \mathrm{MeOH})$.

\begin{tabular}{|c|c|c|c|}
\hline \multicolumn{4}{|c|}{ Interatomic Distances $(\AA)^{a}$} \\
\hline Dy $1 \cdots$ Dy $^{\prime}$ & $3.669(1)$ & Dy1-O8 & $2.527(2)$ \\
\hline Dy1-O1 & $2.265(1)$ & Dy1-N1 & $2.653(2)$ \\
\hline Dy $1 \cdots 1^{\prime}$ & $2.236(1)$ & $\mathrm{N} 2-\mathrm{O} 4$ & $1.261(2)$ \\
\hline Dy1-O2 & $2.363(1)$ & $\mathrm{N} 2-\mathrm{O} 5$ & $1.261(2)$ \\
\hline Dy1-O3 & $2.466(2)$ & $\mathrm{N} 2-\mathrm{O} 6$ & $1.233(2)$ \\
\hline Dy1-O4 & $2.564(2)$ & N3-O7 & $1.280(2)$ \\
\hline Dy1-O5 & $2.492(2)$ & N3-O8 & $1.263(2)$ \\
\hline Dy1-O7 & $2.463(2)$ & N3-O9 & $1.216(2)$ \\
\hline \multicolumn{4}{|c|}{ Bond Angles $(\AA)^{a}$} \\
\hline O1-Dy1-O1' & $70.8(1)$ & O5-Dy1-O1 & $122.3(1)$ \\
\hline O1-Dy1-O2 & $95.5(1)$ & O5-Dy1-O7 & $73.7(1)$ \\
\hline O1-Dy1-O7 & 157.3(1) & O7-Dy1-O8 & $51.2(1)$ \\
\hline $\mathrm{O} 1^{\prime}-\mathrm{Dy} 1-\mathrm{O} 3$ & $149.6(1)$ & O8-Dy1-O5 & 67.7(1) \\
\hline O2-Dy1-O5 & 136.2(1) & N1-Dy1-O2 & $65.8(1)$ \\
\hline O2-Dy1-O7 & $78.4(1)$ & N1-Dy1-O5 & 144.5(1) \\
\hline O3-Dy1-O5 & $77.9(1)$ & Dy1-O1-Dy1 $1^{\prime}$ & 109.2(1) \\
\hline O3-Dy1-O8 & $114.8(1)$ & $\mathrm{O} 4-\mathrm{N} 2-\mathrm{O} 5$ & $117.4(2)$ \\
\hline O4-Dy1-O5 & $50.4(1)$ & $\mathrm{O} 4-\mathrm{N} 2-\mathrm{O} 6$ & $120.9(2)$ \\
\hline O4-Dy1-O7 & $113.2(1)$ & O5-N2-O6 & $121.7(2)$ \\
\hline
\end{tabular}

Table 3. Selected bond lengths $(\AA)$ and angles $\left(^{\circ}\right)$ for complex $\left[\operatorname{Pr}\left(\mathrm{NO}_{3}\right)\left(\operatorname{teaH}_{3}\right)_{2}\right]\left(\mathrm{NO}_{3}\right)_{2}$.

\begin{tabular}{|c|c|c|c|}
\hline \multicolumn{4}{|c|}{ Bond Lengths (Å) } \\
\hline Pr1-O1 & $2.514(1)$ & N2-O5 & $1.224(2)$ \\
\hline Pr1-O2 & $2.502(1)$ & $\mathrm{N} 1-\mathrm{C} 1 \mathrm{~A}$ & $1.487(4)$ \\
\hline Pr1-O3 & $2.521(1)$ & $\mathrm{C} 1 \mathrm{~A}-\mathrm{C} 2 \mathrm{~A}$ & $1.518(4)$ \\
\hline Pr1-O4 & $2.584(1)$ & $\mathrm{C} 2 \mathrm{~A}-\mathrm{O} 1$ & $1.429(2)$ \\
\hline Pr1-N1 & $2.743(1)$ & $\mathrm{C} 3-\mathrm{O} 2$ & $1.434(2)$ \\
\hline $\mathrm{N} 2-\mathrm{O} 4$ & $1.271(1)$ & $\mathrm{C} 5-\mathrm{O} 3$ & $1.430(2)$ \\
\hline \multicolumn{4}{|c|}{ Bond Angles $\left({ }^{\circ}\right)^{a}$} \\
\hline O1-Pr1-O2 & $115.6(1)$ & O4-Pr1-O4' & $49.6(1)$ \\
\hline O1-Pr1-O3 & $77.1(1)$ & O4-Pr1-N1 & $82.5(1)$ \\
\hline O1-Pr1-O4 & $69.6(1)$ & $\mathrm{O} 4^{\prime}-\mathrm{Pr} 1-\mathrm{N} 1$ & $122.5(1)$ \\
\hline O1-Pr1-N1 & $63.4(1)$ & $\mathrm{O} 4-\mathrm{N} 2-\mathrm{O} 4^{\prime}$ & $116.9(2)$ \\
\hline $\mathrm{O} 2-\mathrm{Pr} 1-\mathrm{O} 2^{\prime}$ & $172.0(5)$ & $\mathrm{O} 4-\mathrm{N} 2-\mathrm{O} 5$ & $121.6(1)$ \\
\hline O3-Pr1-O3' & $70.2(1)$ & $\mathrm{C} 1 \mathrm{~A}-\mathrm{C} 2 \mathrm{~A}-\mathrm{O} 1$ & 107.4(2) \\
\hline N1-Pr1-Nq' & 154.1(1) & C6-C5-O3 & 108.1(1) \\
\hline
\end{tabular}

To estimate the closer coordination polyhedron defined by the donor atoms around Dy1 (and its centrosymmetric equivalent), a comparison of the experimental structural data with the theoretical data for the most common polyhedral structures with nine vertices was performed by means of the program SHAPE [47]. The so-called Continuous Shape Measures (CShM) approach essentially allows one to numerically evaluate by how much a particular structure deviates from an ideal shape. As there are no Platonic, Archimedean or Catalan polyhedra with nine vertices, and as no prisms or antiprisms can be constructed with an odd number of vertices, the main semiregular three-dimensional figures that may be considered are those listed (except, of course, the enneagon) in Table S1. The best fit (Table S1) was obtained for the spherical capped square antiprism (Figure S6), with the nitrato oxygen atom $\mathrm{O} 4$ being the capping atom.

The lattice structure of the complex is built through $\mathrm{H}$ bonds (Table S5) involving the $\mathrm{MeOH}$ oxygen atom $(\mathrm{O} 1 \mathrm{M})$ and the neutral hydroxyl oxygen atoms $(\mathrm{O} 2$, and $\mathrm{O} 3)$ as donors, and the $\mathrm{O} 1 \mathrm{M}, \mathrm{O} 3$ and nitrato oxygen atoms $\mathrm{O} 4$ and $\mathrm{O} 6$ as acceptors; thus, $\mathrm{O} 1 \mathrm{M}$ and $\mathrm{O} 3$ act as both donors and acceptors of $\mathrm{H}$ bonds. A weak, non-classical $\mathrm{H}$ bond is also formed with the teaH ${ }_{2}{ }^{-}$carbon atom $\mathrm{C} 2$ (this is the 
atom that is connected to $\mathrm{N} 1$ ) as donor and the nitrato oxygen atom $\mathrm{O} 8$ as acceptor. The $\mathrm{O}-\mathrm{H} \cdots \mathrm{O} \mathrm{H}$ bonds create chains parallel to the $a$ axis (Figure 3).

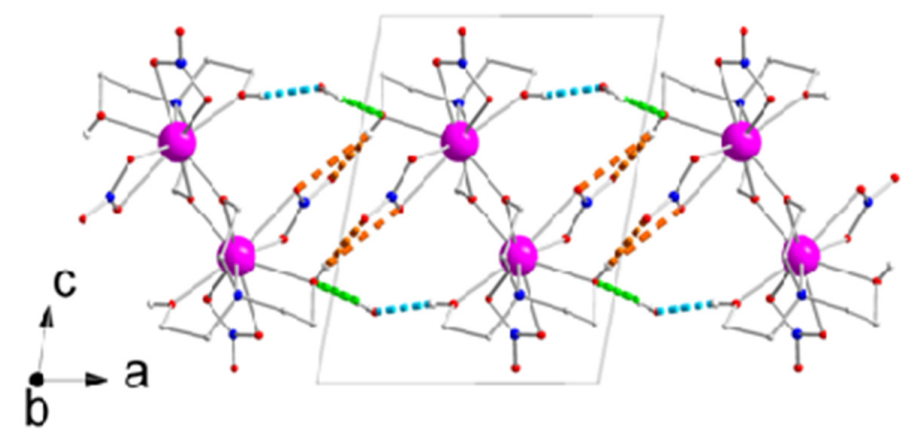

Figure 3. Chains of molecules formed parallel to the $a$ axis in the crystal structure of $4 \cdot 2 \mathrm{MeOH}$. The thick

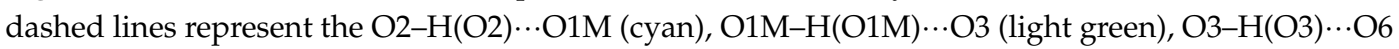
and $\mathrm{O} 3-\mathrm{H}(\mathrm{O} 3) \cdots \mathrm{O} 4$ (orange) $\mathrm{H}$ bonds.

The $\mathrm{Ln}-\mathrm{O} / \mathrm{N}$ bond lengths and the $\mathrm{Ln} \cdots \mathrm{Ln}$ distances in the isomorphous complexes $1 \cdot 2 \mathrm{MeOH}$, 2.2MeOH and 4.2MeOH follow the order Dy $<\mathrm{Gd}<\operatorname{Pr}$ (for example the Dy $\cdots$ Dy, Gd $\cdots \mathrm{Gd}$ and $\operatorname{Pr} \cdots \operatorname{Pr}$ distances are 3.669(1), 3.719(1) and 3.810(1) $\AA$, respectively), a typical consequence of the lanthanide(III) contraction [25]. The coordination polyhedra of the $\mathrm{Gd}^{\mathrm{III}}(\mathbf{2} \cdot 2 \mathrm{MeOH})$ and $\operatorname{Pr}^{\mathrm{III}}(\mathbf{1} \cdot 2 \mathrm{MeOH})$ are closest to Johnson tricapped trigonal prism and to spherical-relaxed capped cube, respectively (Figures S7 and S8, respectively; Tables S2 and S3, respectively). At first glance, the fact that the $\mathrm{Ln}^{\mathrm{III}}$ centers in the isomorphous complexes $1 \cdot 2 \mathrm{MeOH}, 2 \cdot 2 \mathrm{MeOH}$ and $\mathbf{4} \cdot 2 \mathrm{MeOH}$ have different coordination geometries (and not consistent CShM values) seems strange. We attribute this to two factors: (i) For a given ligand set of nine donor atoms, the tricapped trigonal prism, capped square antiprism and capped cube polyhedra have comparable energies [48,49] and there exist minimal distortion interconversion paths between them; thus many structures are intermediate between two ideal shapes [48], and (ii) the $\mathrm{Ln}^{\mathrm{III}}$-donor atom distances are slightly different due to lanthanide(III) contraction and this can affect the shape. For example, the CShM values of the Dy ${ }^{\mathrm{III}}$ center in $4 \cdot 2 \mathrm{MeOH}$ for the spherical capped square antiprism (3.263), spherical-relaxed capped cube (4.016) and tricapped trigonal prism (4.165) are all low and similar (Table S1), and its polyhedron could be equally well described as spherical-relaxed capped cube (a polyhedron that gives the lowest CShM value for the $\mathrm{Pr}^{\mathrm{III}}$ center in $1 \cdot 2 \mathrm{MeOH}$, Table S3).

Complex 6 crystallizes in the monoclinic space group $C 2 / c$. Its structure consists of mononuclear $\left.\left[\operatorname{Pr}\left(\mathrm{NO}_{3}\right)(\text { teaH })_{2}\right)_{2}\right]^{2+}$ cations and $\mathrm{NO}_{3}{ }^{-}$counterions in a 1:2 ratio; the latter will not be further discussed. The asymmetric unit contains half of the cation and one nitrate anion. The cation has crystallographic twofold symmetry, with Pr1 and the nitrate atoms N2 and O5 occupying the rotation axis. Pr1 is coordinated to two neutral $\eta^{1}: \eta^{1}: \eta^{1}: \eta^{1}$ teaH $\mathrm{H}_{3}$ ligands (A in Scheme 1) and to one bidentate chelating nitrato group, and its coordination number is thus 10 . The $\mathrm{Pr}-\mathrm{O} / \mathrm{N}$ bond lengths are slightly shorter than the corresponding $\mathrm{La}-\mathrm{O} / \mathrm{N}$ ones in the isomorphous compound $\left[\mathrm{La}\left(\mathrm{NO}_{3}\right)\left(\mathrm{teaH}_{3}\right)_{2}\right]\left(\mathrm{NO}_{3}\right)_{2}[35]$. Again, the N2-O5 (1.224(2) $\AA$ ) bond distance involving the uncoordinated nitrato oxygen atom is shorter than the $\mathrm{N} 2-\mathrm{O} 4, \mathrm{O}^{\prime}$ distances (1.271(1) $\AA$ ) involving the bound nitrato oxygen atoms.

Of the accessible 10-coordinate polyhedra for metal ions, the sphenocorona (tetradecahedron) (Figure $4 \mathrm{~b}$ ) is the most appropriate for the description of the 10 donor atoms in $\mathbf{6}$ according to the program SHAPE [47] (Table S4).

Intercationic interactions through the $\mathrm{C} 3-\mathrm{HB}(3) \cdots \mathrm{O} 4$ (and its symmetry equivalent) $\mathrm{H}$ bond result in the formation of chains parallel to the $c$ axis (Figure 5a). Attached to these chains are lattice $\mathrm{NO}_{3}{ }^{-}$ ions through the $\mathrm{O} 1-\mathrm{H}(\mathrm{O} 1) \cdots \mathrm{O} 6$ and $\mathrm{O} 2-\mathrm{H}(\mathrm{O} 2) \cdots \mathrm{O} 8 \mathrm{H}$ bonds (Figure 5a). These lattice $\mathrm{NO}_{3}{ }^{-}$ions interact further through the $\mathrm{O} 3-\mathrm{H}(\mathrm{O} 3) \cdots \mathrm{O} 8$ and $\mathrm{C} 6-\mathrm{HA}(\mathrm{C} 6) \cdots \mathrm{O} 8-\mathrm{H}$ bonds with neighboring chains forming a 3D architecture(Figure $5 \mathrm{~b}$ ). The dimensions of the $\mathrm{H}$ bonds are listed in Table $\mathrm{S6}$. 


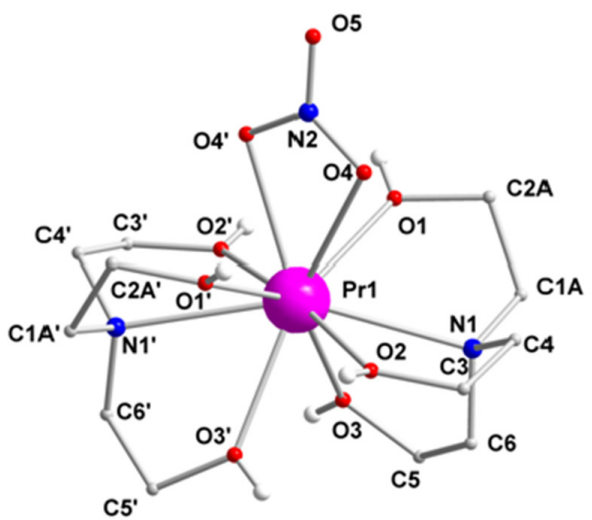

(a)

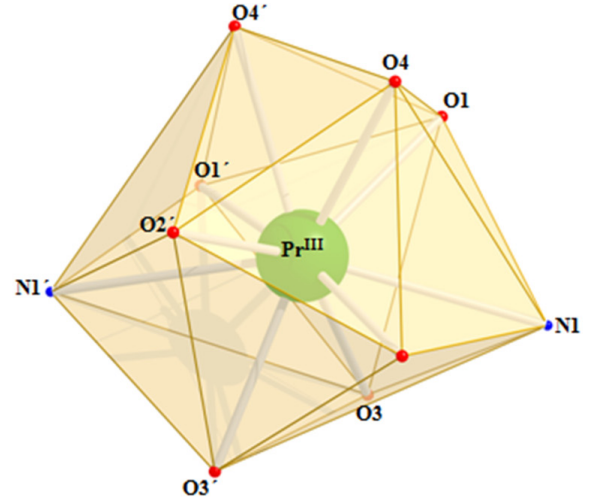

(b)

Figure 4. (a) Labeled plot of the cation $\left[\operatorname{Pr}\left(\mathrm{NO}_{3}\right)\left(\mathrm{teaH}_{3}\right)_{2}\right]^{2+}$ that is present in the structure of 6 . Since the methylene groups of tea $\mathrm{H}_{3}$ defined by the $\mathrm{C} 1$ and $\mathrm{C} 2$ atoms present disorder at two sites, only the carbon atoms of the sites with the 0.8 occupancy have been drawn. Symmetry operation used to generate equivalent atoms: $\left({ }^{\prime}\right)-x+1, y,-z+1 / 2$. Only the $H$ atoms of the hydroxyl groups are shown. (b) The sphenocoronal coordination geometry of Pr1 in the structure of $\mathbf{6}$. The plotted polyhedron is the ideal, best-fit polyhedron using the program SHAPE [47]. Primed and unprimed donor atoms are related by the symmetry operation $-x+1, y,-z+1 / 2$.

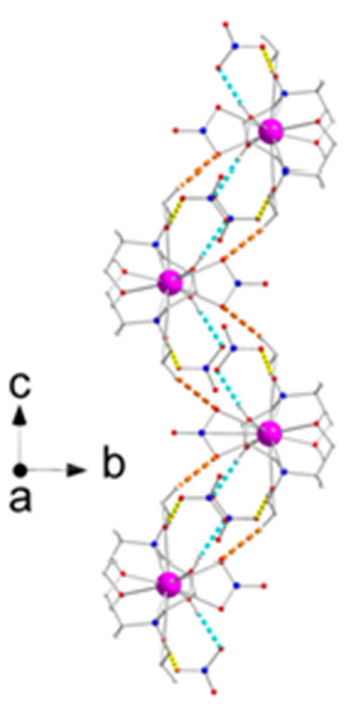

(a)

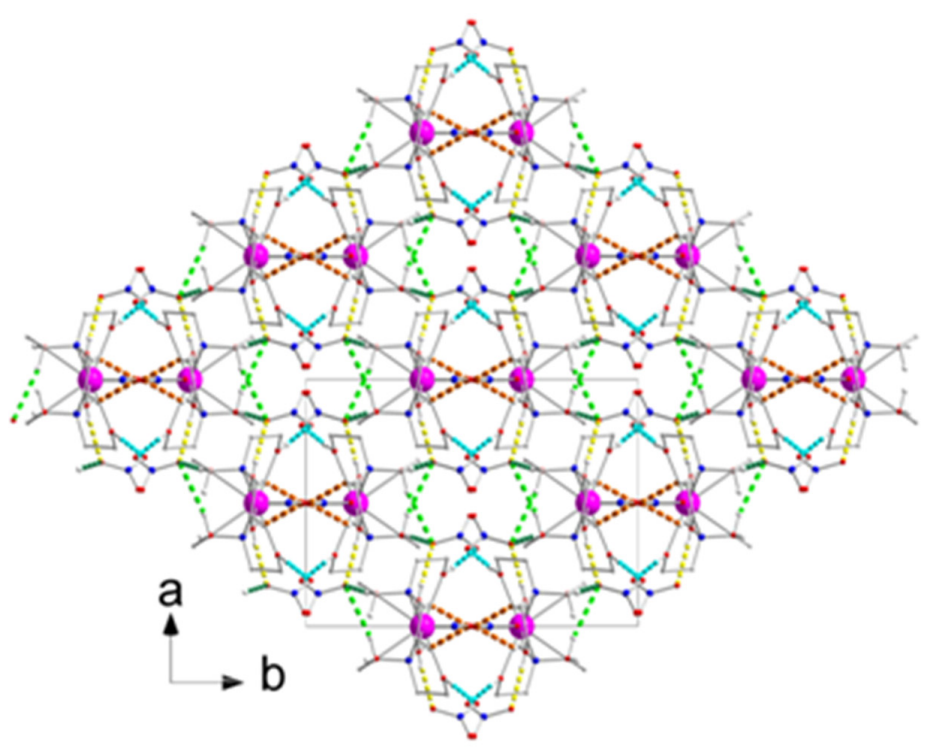

(b)

Figure 5. (a) Chains of $\left.\left[\operatorname{Pr}\left(\mathrm{NO}_{3}\right)(\text { teaH})_{3}\right)_{2}\right]^{2+}$ cations and $\mathrm{NO}_{3}{ }^{-}$counterions parallel to the $c$ axis in the crystal structure of $\mathbf{6}$. (b) $3 \mathrm{D}$ arrangement of chains in the crystal structure of $\mathbf{6}$. The thick

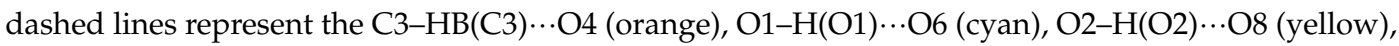

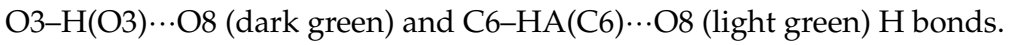

Complexes 1-6 join a small family of homometallic $\mathrm{Ln}^{\mathrm{III}}$ complexes containing triethanolamine, and its singly and doubly deprotonated forms as ligands (Table 4); $\mathrm{Ln}^{\mathrm{III}} / \mathrm{tea}^{3-}$ complexes are not known. Complexes 1, 2 and 4 are the only dinuclear $\mathrm{Ln}^{\mathrm{III}}$ complexes that possess a form of triethanolamine as the only organic ligand. Complex 6 is isomorphous with $\left[\mathrm{La}\left(\mathrm{NO}_{3}\right)\left(\mathrm{teaH}_{3}\right)_{2}\right]\left(\mathrm{NO}_{3}\right)_{2}$ [35]. Of particular interest is the ability of teaH $\mathrm{H}_{3}$ to stabilize homoleptic cationic complexes with the divalent lanthanides $\mathrm{Eu}^{\mathrm{II}}$ and $\mathrm{Yb}^{\mathrm{II}}[33,34]$. 
Table 4. Crystallographically characterized homometallic $\mathrm{Ln}^{\mathrm{II}}$ and $\mathrm{Ln}^{\mathrm{III}}$ complexes containing the teaH ${ }_{3}$, teaH ${ }_{2}^{-}$and teaH ${ }^{2-}$ groups as ligands.

\begin{tabular}{|c|c|c|c|}
\hline Complex $^{\mathrm{a}}$ & Coordination Mode $^{\mathrm{b}}$ & Coordination Polyhedra & Ref. \\
\hline 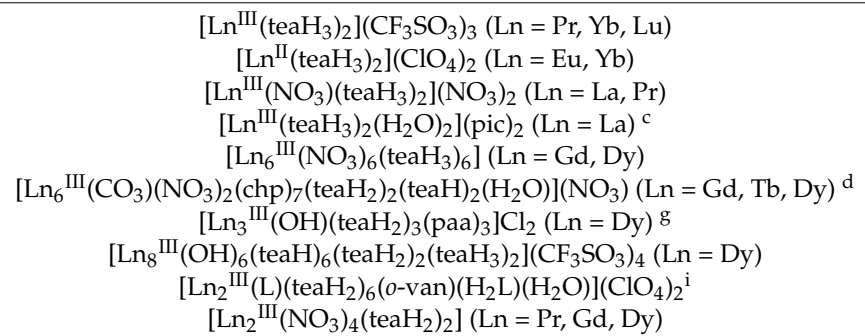 & $\begin{array}{c}\eta^{1}: \eta^{1}: \eta^{1}: \eta^{1}(\mathrm{~A}) \\
\eta^{1}: \eta^{1}: \eta^{1}: \eta^{1}(\mathrm{~A}) \\
\eta^{1}: \eta^{1}: \eta^{1}: \eta^{1}(\mathrm{~A}) \\
\eta^{1}: \eta^{1}: \eta^{1}: \eta^{1}(\mathrm{~A}) \\
\eta^{1}: \eta^{1}: \eta^{2}: \eta^{2}: \mu_{3}(\mathrm{E}) \\
\eta^{1}: \eta^{1}: \eta^{1}: \eta^{3}: \mu_{3}(\mathrm{C})^{\mathrm{e}}, \eta^{1}: \eta^{1}: \eta^{2}: \eta^{2}: \mu_{3}(\mathrm{E})^{\mathrm{f}} \\
\eta^{1}: \eta^{1}: \eta^{1}: \eta^{2}: \mu_{2}(\mathrm{~B}) \\
\eta^{1}: \eta^{1}: \eta^{1}: \eta^{3}: \mu_{3}(\mathrm{G})^{\mathrm{f}}, \eta^{1}: \eta^{1}: \eta^{1}: \eta^{2}: \mu_{2}(\mathrm{~F})^{\mathrm{f}}, \eta^{1}: \eta^{1}: \eta^{1}: \eta^{1}(\mathrm{~A}, \mathrm{D}) \mathrm{h} \\
\eta^{1}: \eta^{\mathrm{h}}: \eta^{:}: \eta^{2}: \mu_{2}(\mathrm{~B}) \\
\eta^{1}: \eta^{1}: \eta^{1}: \eta^{2}: \mu_{2}(\mathrm{~B})\end{array}$ & 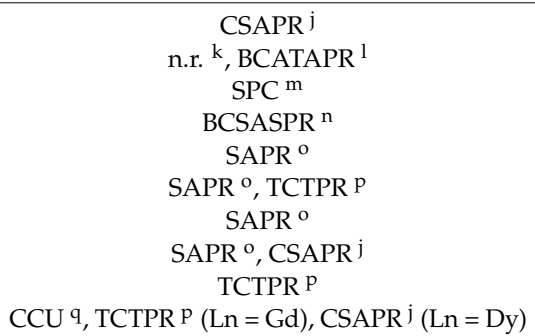 & $\begin{array}{c}{[32]} \\
{[33,34]} \\
{[35], \text { this work }} \\
{[36]} \\
{[37]} \\
{[38]} \\
{[39]} \\
{[39]} \\
{[40]} \\
\text { this work }\end{array}$ \\
\hline
\end{tabular}

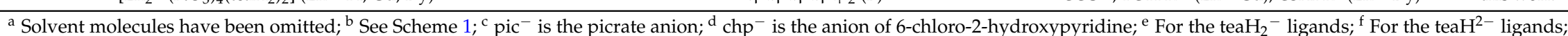

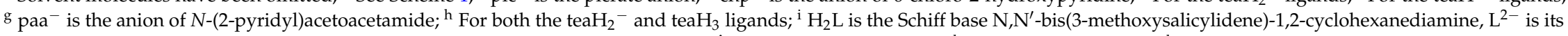

dianionic form and $o$-van ${ }^{-}$is the anion of 3-methoxysalicylaldehyde (ortho-vanillin); ${ }^{\mathrm{j}}$ Capped square antiprism; ${ }^{\mathrm{k}}$ For the Eu(II) complex; ${ }^{\mathrm{l}}$ Bicapped trigonal antiprism; ${ }^{\mathrm{m}}$ Sphenocorona;

${ }^{n}$ Bicapped square antiprism; ${ }^{\circ}$ Square antiprism; ${ }^{\mathrm{P}}$ Tricapped trigonal prism; ${ }^{q}$ Capped cube (for the $\mathrm{Pr}_{2}$ complex). 


\subsection{Magnetic Susceptibility Studies}

Direct current $(\mathrm{dc})$ magnetic susceptibility data $\left(\mathrm{X}_{\mathrm{M}}\right)$ on dried polycrystalline, analytically pure samples of 2-5 were collected in the 2.0-300 K range. The data are plotted as $\chi_{\mathrm{M}} T$ vs. $T$ products in Figure 6. The strength of the magnetic interactions between the two $\mathrm{Ln}^{\mathrm{III}}$ ions in the dinuclear complexes can be easily quantified with the gadolinium analog 2 . Indeed, the $\mathrm{Gd}^{\mathrm{III}}$ ions present no spin-orbit coupling at the first order. Thus, the decrease or increase of the $\chi_{M} T$ product when lowering the temperature for 2 reveals directly the presence of an antiferromagnetic or ferromagnetic, respectively, interaction between the $\mathrm{Gd}^{\mathrm{III}}$ centers. The room temperature $\mathrm{\chi}_{\mathrm{M}} T$ value for 2 is $16.10 \mathrm{~cm}^{3} \cdot \mathrm{K} \cdot \mathrm{mol}^{-1}$, essentially equal to the spin-only value $\left(15.75 \mathrm{~cm}^{3} \cdot \mathrm{K} \cdot \mathrm{mol}^{-1}\right)$ expected for two non-interacting $\mathrm{Gd}^{\mathrm{III}}\left({ }^{8} S_{7 / 2}, S=7 / 2, L=0, g=2\right)$ ions. The value of the $\chi_{\mathrm{M}} T$ product remains almost constant down to $\sim 40 \mathrm{~K}$ and then decreases rapidly to $4.64 \mathrm{~cm}^{3} \cdot \mathrm{K} \cdot \mathrm{mol}^{-1}$ at $2.0 \mathrm{~K}$, suggesting an antiferromagnetic exchange interaction. Fit of the experimental data was performed by means of the conventional analytical expression derived from the isotropic spin Hamiltonian shown in Equation (3).

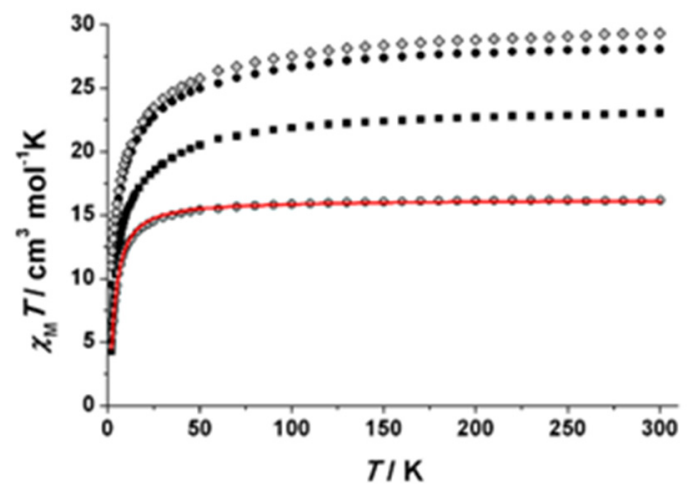

Figure 6. $\chi_{M} T$ vs. $T$ plots for compounds 2 (open circles), 3 (solid squares), 4 (solid circles) and 5 (open diamonds). The solid line is the fit of the data to the theoretical model for the $\mathrm{Gd}^{\mathrm{III}}{ }_{2}$ complex 2; see the text for the fit parameters.

The best-fit parameters for the simultaneous simulation of susceptibility and magnetization data are $J=-0.30(1)$ and $g=2.03 \mathrm{~cm}^{-1}$ with $R$ values of $6.1 \times 10^{-5}\left(\chi_{\mathrm{M}} T\right)$ and $1.2 \times 10^{-4}(M)$. As expected for pure $\mathrm{Ln}^{\mathrm{III}}$ systems, the exchange interaction is rather weak as a consequence of the shielded $4 \mathrm{f}$ orbitals that have small overlap with bridging ligand orbitals. This $J$ value is typical for dinuclear complexes containing the $\left\{\mathrm{Gd}^{\mathrm{III}}{ }_{2}\left(\mu_{2}-\mathrm{OR}\right)_{2}\right\}^{4+}$ core $[17,18,20,25,50]$. Rov and Hughbanks performed a spin density functional (SDFT) study of dinuclear $\mathrm{Gd}^{\mathrm{III}}$ complexes containing the $\left\{\mathrm{Gd}_{2}\left(\mu_{2}-\mathrm{OR}\right)_{2}\right\}^{4+}$ core [20]. The systematic study showed that symmetrically bridged complexes are antiferromagnetically coupled and asymmetrically bridged ones are ferromagnetically coupled. In the case of 2 , the $\left\{\mathrm{Gd}_{2}{ }^{\mathrm{III}}\left(\mu_{2}-\mathrm{OR}\right)_{2}\right\}^{4+}$ core shows near- $D_{2 \mathrm{~h}}$ symmetry; the $\mathrm{Gd}-\left(\mu_{2}-\mathrm{OR}\right)$ bond distances are nearly equal $\left(2.258(1)\right.$ and 2.303(1) $\AA$ ) and the $C-\left(\mu_{2}-\mathrm{O}\right)-\mathrm{Gd}$ angles are in the relatively narrow range 119.3(1)-130.5(1) . Thus, the antiferromagnetic $\mathrm{Gd}^{\mathrm{III}} \ldots \mathrm{Gd}^{\mathrm{III}}$ exchange interaction in 2 is in accordance with the theoretical predictions [20].

$$
\hat{H}=-J\left(\hat{S}_{\mathrm{Gd} 1} \cdot \hat{S}_{\mathrm{Gd} 11}\right)
$$

The room temperature $\chi_{\mathrm{M}} T$ values for $3\left(23.04 \mathrm{~cm}^{3} \cdot \mathrm{K} \cdot \mathrm{mol}^{-1}\right), 4\left(28.07 \mathrm{~cm}^{3} \cdot \mathrm{K}^{\mathrm{m}} \cdot \mathrm{mol}^{-1}\right)$ and 5 $\left(29.32 \mathrm{~cm}^{3} \cdot \mathrm{K} \cdot \mathrm{mol}^{-1}\right)$ are in agreement with the expected theoretical values of 23.64, 28.34 and $28.14 \mathrm{~cm}^{3} \cdot \mathrm{K} \cdot \mathrm{mol}^{-1}$ for two non-interacting $\mathrm{Tb}^{\mathrm{III}}\left({ }^{7} F_{6}, S=3, L=3, g=3 / 2\right)$, Dy ${ }^{\mathrm{III}}\left({ }^{6} H_{15 / 2}, S=5 / 2\right.$, $\left.L=5, g_{j}=4 / 3\right)$ and $\mathrm{Ho}^{\mathrm{III}}\left({ }^{5} I_{8}, S=2, L=6, g_{j}=5 / 4\right)$ centers respectively. In all the three cases, the $\chi_{\mathrm{M}} T$ product decreases slightly between 300 and $\sim 50 \mathrm{~K}$, before a more rapid decrease below $\sim 30 \mathrm{~K}$, to reach values of $4.24(3), 9.52(4)$ and $11.02(5) \mathrm{cm}^{3} \cdot \mathrm{K} \cdot \mathrm{mol}^{-1}$ at $2.0 \mathrm{~K}$. For such $\mathrm{Ln}{ }^{\mathrm{III}}$ ions with an unquenched 
orbital moment associated with a ligand field, the decrease of the $\chi_{M} T$ product as the temperature is lowered can originate from the following possible contributions [50]: (a) the thermal depopulation of the Stark sublevels; (b) the presence of magnetic anisotropy; and (c) antiferromagnetic interactions between the $\mathrm{Ln}^{\mathrm{III}}$ centers. The relatively low $\chi_{\mathrm{M}} T$ values at $2.0 \mathrm{~K}$ may suggest the contribution of a weak to moderate $\mathrm{Ln}^{\mathrm{III}} \ldots \mathrm{Ln}^{\mathrm{III}}$ interaction $(\mathrm{Ln}=\mathrm{Tb}, \mathrm{Dy}, \mathrm{Ho})$, as confirmed for the Gd ${ }_{2}{ }_{2}$ complex 2. This assumption is further validated by the presence of a maximum in the $\chi_{\mathrm{M}}$ vs. $T$ plot at $3.3 \mathrm{~K}$ for the $\mathrm{Tb}^{\mathrm{III}}{ }_{2}$ complex 3 .

Magnetization plots for $\mathbf{2}-\mathbf{5}$ are shown in Figure 7. As a consequence of the antiferromagnetic interaction between the spin carriers, the shape of the plots is clearly sigmoid for 2 and 3 , this effect being less pronounced for 4 and almost negligible for the $\mathrm{Ho}^{\mathrm{III}}$ analog 5 .

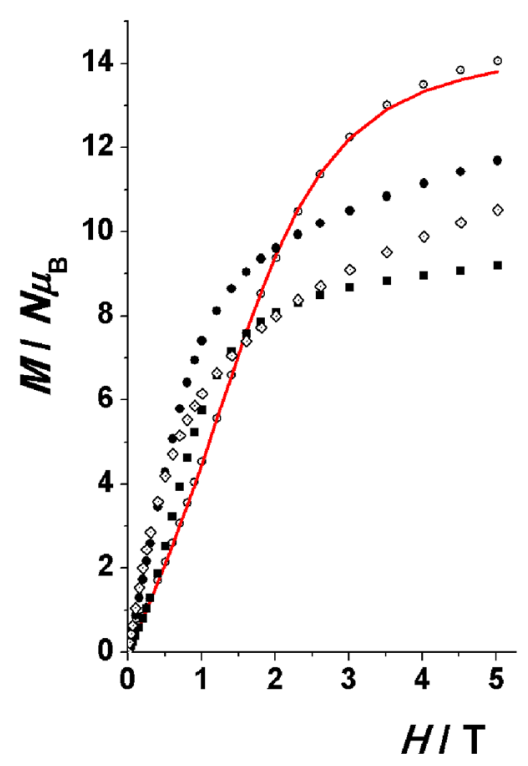

(a)

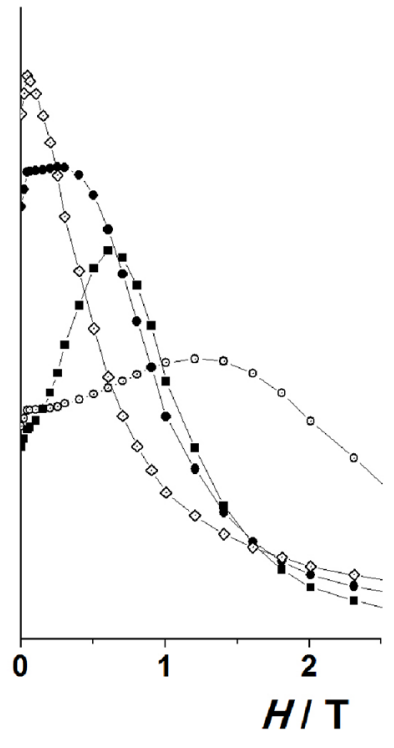

(b)

Figure 7. (a) Magnetization plots at $2.0 \mathrm{~K}$ for compounds 2 (open circles), 3 (solid squares), 4 (solid circles) and $\mathbf{5}$ (open diamonds). The solid line is the fit of the data to the theoretical model for the $\mathrm{Gd}_{2}{ }_{2}$ complex 2. (b) First derivative of the magnetization plots evidencing their sigmoid shape.

In order to investigate the presence of slow relaxation of the magnetization which might originate from an SMM behavior, alternating current (ac) magnetic susceptibility measurements were performed on powdered samples of 3-5 in the temperature range 2.0-12 K with zero dc field and a $4.0 \mathrm{G}$ ac field oscillating in the $10-1500 \mathrm{~Hz}$ range. Unfortunately, no frequency dependent out-of-phase $\left(\chi_{M}^{\prime \prime}\right)$ signals were detected for the complexes. This was rather surprising for 4 , because dysprosium(III) is a Kramers' ion (it has an odd number of $4 \mathrm{f}$ electrons), meaning that the ground state will always be bistable (one of the prerequisites for a molecule to be an SMM) irrespective of the ligand field symmetry. A review by Rinehart and Long five years ago [51] has provided a lucid account of how f-element electronic structure can, in principle, be manipulated to create new SMMS. The basic overall shape of free-ion electron density is oblate (i.e., it extends into the $x y$ plane) for $\mathrm{Tb}^{\mathrm{III}}$, $\mathrm{Dy}^{\mathrm{III}}$ and $\mathrm{Ho}^{\mathrm{III}}$ in their ground states. Therefore, to maximize the anisotropy of an oblate ion (and thus the chances to observe SMM properties), we should place it in a crystal field for which the ligand electron density is concentrated above and below the $x y$ plane; this is clearly not the case here. Given that in the absence of high symmetry (as in 4), the ground state of Dy ${ }^{\mathrm{III}}$ is a doublet along the anisotropy axis with an angular momentum quantum number $m_{j}= \pm 15 / 2$, we have determined the orientation of the ground state magnetic anisotropy axis for the Dy ${ }^{\mathrm{III}}$ center of 4 using a method reported in 2013 [52], based on an electrostatic model. This method does not demand the fitting of experimental data; it only requires the knowledge of the single-crystal X-ray structure of the complex. Following this method and the 
program MAGELLAN (a FORTRAN program), the ground state magnetic anisotropy axis for each Dy III ion (the two axis are co-parallel due to the existence of the crystallographically imposed inversion center in the molecule) is directed towards the bridging oxygen atoms $\mathrm{O} 1 / \mathrm{O}^{\prime}$ (Figure 8), which exhibit the shortest Dy-O bond distances (Table 2). This forces the oblate electron density of Dy ${ }^{\mathrm{III}}$ to be almost parallel to the easy axis, which is a non-favorable spatial conformation to achieve slow relaxation of the magnetization [52]. No frequency dependent out-of-phase ac magnetic susceptibility signals were observed for $\mathbf{3}-\mathbf{5}$ under external dc fields of 0.1 and $0.2 \mathrm{~T}$, suggesting that the complexes are not field-induced SMMs.

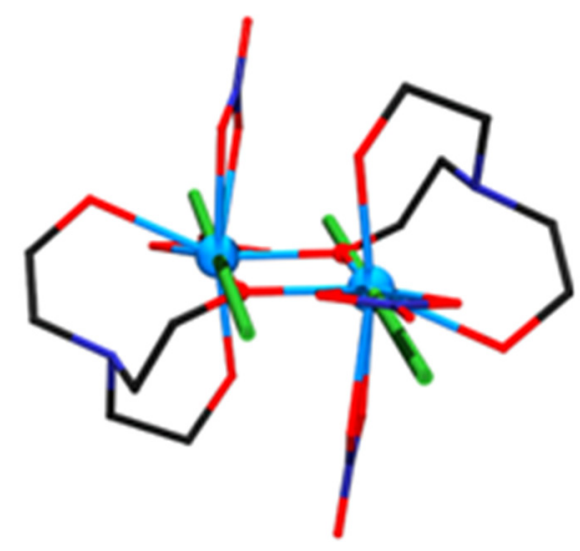

Figure 8. Ground state magnetic anisotropy axis (green bars) for the two symmetry-related Dy ${ }^{\mathrm{III}}$ ions that are present in the molecule of 4 .

Since the $\mathrm{Ln}^{\mathrm{III}}$ ions most often used in SMMs are $\mathrm{Tb}^{\mathrm{III}}, \mathrm{Dy}{ }^{\mathrm{III}}, \mathrm{Ho}^{\mathrm{III}}$ and $\mathrm{Er}^{\mathrm{III}}$ (and rarely $\mathrm{Yb}^{\mathrm{III}}$ ) and since there are no reports of $\operatorname{Pr}^{\mathrm{III}}$ SMMs [6], we have not studied the magnetic properties of the $\operatorname{Pr}^{\mathrm{III}}$ complexes $\mathbf{1}$ and $\mathbf{6}$.

\section{Experimental Section}

\subsection{Materials and Physical Measurements}

All manipulations were performed under aerobic conditions using reagents and solvents (Alfa Aesar, Aldrich; Karlsruhe, Germany and Tanfrichen, Germany, respectively) as received. Elemental analyses $(\mathrm{C}, \mathrm{H}, \mathrm{N})$ were carried out by the University of Patras microanalytical service (Patras, Greece). FT-IR spectra (4000-400 $\mathrm{cm}^{-1}$ ) were recorded using a Perkin-Elmer (supplier, Watham, MA, USA) 16 PC FT-IR spectrometer with samples prepared as $\mathrm{KBr}$ pellets and as nujol or hexachlorobutadiene mulls between CsI disks. Solid state, variable-temperature direct-current (dc) magnetic susceptibility data were collected on powdered samples of representative complexes using a MPMS5 Quantum Design (supplier, San Diego, CA, USA) SQUID magnetometer, operating at dc fields of $0.3 \mathrm{~T}$ in the 300-30 K range and $0.03 \mathrm{~T}$ in the $30-2.0 \mathrm{~K}$ range to avoid saturation effects at low temperatures. Diamagnetic corrections were applied to observed paramagnetic susceptibilities using Pascal's constants [53]. The fit of the experimental data for the dinuclear $\mathrm{Gd}^{\mathrm{III}}$ complex was performed with the PHI program [54]. The quality of the fits was parameterized using the factor $R=\left\{\left(\chi_{M} T\right)_{\exp }-\left(\chi_{M} T\right)_{\text {calcd }}\right\}^{2} /\left\{\left(\chi_{M} T\right)_{\exp }\right\}^{2}$.

\subsection{Synthesis of $\left[\mathrm{Pr}_{2}\left(\mathrm{NO}_{3}\right)_{4}\left(t e a \mathrm{H}_{2}\right)_{2}\right] \cdot 2 \mathrm{MeOH}(\mathbf{1} \cdot 2 \mathrm{MeOH})$}

To a stirred colorless solution of teaH $\mathrm{H}_{3}(66 \mu \mathrm{L}, 0.50 \mathrm{mmol})$ in $\mathrm{MeOH}(20 \mathrm{~mL})$ was added solid $\operatorname{Pr}\left(\mathrm{NO}_{3}\right)_{3} \cdot 6 \mathrm{H}_{2} \mathrm{O}(0.218 \mathrm{~g}, 0.50 \mathrm{mmol})$. The solid soon dissolved and the resulting very pale green (almost colorless) solution was stirred for a further $10 \mathrm{~min}$ and left undisturbed in a closed flask at room temperature. X-ray quality, pale green crystals of the product were formed over a period of $4-5$ days. The crystals were collected by filtration, washed with cold $\mathrm{MeOH}(1 \mathrm{~mL})$ and $\mathrm{Et}_{2} \mathrm{O}$ 
$(3 \times 1 \mathrm{~mL})$, and dried in air. Typical yields were in the range $40 \%-45 \%$ (based on the $\mathrm{Pr}^{\mathrm{III}}$ available). The complex was satisfactorily analyzed as lattice $\mathrm{MeOH}$-free, i.e., as $\mathbf{1}$. Anal calc. for $\mathrm{C}_{12} \mathrm{H}_{28} \mathrm{~N}_{6} \mathrm{Pr}_{2} \mathrm{O}_{18}$ (found values in parentheses): C 17.44 (17.63), H 3.42 (3.36), N $10.17(9.87) \%$. IR bands $\left(\mathrm{KBr} \mathrm{cm}^{-1}\right)$ : 3356 sb, 3150 m, 2930 m, 1650 m, 1458 m, 1406 sh, 1384 s, 1094 m, 1084 m, 1064 w, 1032 m, 1004 m, $916 \mathrm{~m}, 832 \mathrm{w}, 818 \mathrm{w}, 738 \mathrm{w}, 670 \mathrm{w}, 564 \mathrm{~m}, 544 \mathrm{w}, 526 \mathrm{w}, 458 \mathrm{wb}, 402 \mathrm{w}$.

\subsection{Syntheses of $\left[\mathrm{Gd}_{2}\left(\mathrm{NO}_{3}\right)_{4}\left(t e a \mathrm{H}_{2}\right)_{2}\right] \cdot 2 \mathrm{MeOH}(2 \cdot 2 \mathrm{MeOH}),\left[\mathrm{Tb}_{2}\left(\mathrm{NO}_{3}\right)_{4}\left(t e a \mathrm{H}_{2}\right)_{2}\right] \cdot 2 \mathrm{MeOH}(3 \cdot 2 \mathrm{MeOH})$, $\left[\mathrm{Dy}_{2}\left(\mathrm{NO}_{3}\right)_{4}\left(\mathrm{teaH} \mathrm{H}_{2}\right] \cdot 2 \mathrm{MeOH}(4 \cdot 2 \mathrm{MeOH})\right.$ and $\left[\mathrm{Ho}_{2}\left(\mathrm{NO}_{3}\right)_{4}\left(\mathrm{teaH}_{2}\right)_{2}\right] \cdot 2 \mathrm{MeOH}(5 \cdot 2 \mathrm{MeOH})$}

These complexes were prepared and crystallized in an identical manner with $1 \cdot 2 \mathrm{MeOH}$ by simply replacing $\operatorname{Pr}\left(\mathrm{NO}_{3}\right)_{3} \cdot 6 \mathrm{H}_{2} \mathrm{O}$ with $\mathrm{Gd}\left(\mathrm{NO}_{3}\right)_{3} \cdot 6 \mathrm{H}_{2} \mathrm{O}(0.226 \mathrm{~g}, 0.50 \mathrm{mmol}), \mathrm{Tb}\left(\mathrm{NO}_{3}\right)_{3} \cdot 6 \mathrm{H}_{2} \mathrm{O}(0.227 \mathrm{~g}$, $0.50 \mathrm{mmol}), \mathrm{Dy}\left(\mathrm{NO}_{3}\right)_{3} \cdot 5 \mathrm{H}_{2} \mathrm{O}(0.219 \mathrm{~g}, 0.50 \mathrm{mmol})$ and $\mathrm{Ho}\left(\mathrm{NO}_{3}\right)_{3} \cdot 6 \mathrm{H}_{2} \mathrm{O}(0.230 \mathrm{~g}, 0.50 \mathrm{mmol})$. The crystals of all the complexes were colorless. Typical yields were $\sim 45 \%$ for $2, \sim 55 \%$ for $3, \sim 35 \%$ for 4 and $\sim 40 \%$ for 5 . The complexes were satisfactorily analyzed as lattice $\mathrm{MeOH}$-free. Anal. calc. for $\mathrm{C}_{12} \mathrm{H}_{28} \mathrm{~N}_{6} \mathrm{Ln}_{2} \mathrm{O}_{18}$ (found values in parentheses): 2 ( $\mathrm{Ln}=\mathrm{Gd}$ ): C 16.78 (16.93), $\mathrm{H} 3.29$ (3.40), N 9.79 (9.55)\%; 3 (Ln = Tb): C 16.71 (16.39), H 3.28 (3.31), N 9.75 (9.50)\%; 4 (Ln = Dy): C 16.58 (16.70), H 3.25 (3.37), N 9.67 (9.71)\%; 5 ( Ln = Ho): C 16.48 (16.31), H 3.23 (3.30), N 9.61 (9.42)\%. The IR spectra of 2, 3, $\mathbf{4}$ and $\mathbf{5}$ are almost superimposable with the spectrum of $\mathbf{1}$ with a maximum wavenumber difference of $\pm 4 \mathrm{~cm}^{-1}$.

\subsection{Synthesis of $\left[\operatorname{Pr}\left(\mathrm{NO}_{3}\right)\left(t e a \mathrm{H}_{3}\right)_{2}\right]\left(\mathrm{NO}_{3}\right)_{2}$ (6)}

To a stirred colorless solution of teaH $\mathrm{H}_{3}(330 \mu \mathrm{L}, 2.50 \mathrm{mmol})$ in $\mathrm{MeOH}(12 \mathrm{~mL})$ was added dropwise a solution of $\operatorname{Pr}\left(\mathrm{NO}_{3}\right)_{3} \cdot 6 \mathrm{H}_{2} \mathrm{O}(0.435 \mathrm{~g}, 1.00 \mathrm{mmol})$ in the same solvent $(5 \mathrm{~mL})$. The resulting very pale green (almost colorless) solution was stirred for a further $15 \mathrm{~min}$. The undisturbed solution was allowed to slowly evaporate in an open flask at room temperature. X-ray quality, pale green crystals of the product were grown over a period of $2-3 \mathrm{~d}$. When precipitation was judged to be complete, the crystals were collected by filtration, washed with cold $\mathrm{MeOH}(0.5 \mathrm{~mL})$ and $\mathrm{Et}_{2} \mathrm{O}(5 \times 1 \mathrm{~mL})$, and dried in air. The yield was $62 \%$ (based on the $\operatorname{Pr}^{\mathrm{III}}$ available). Anal. calc. for $\mathrm{C}_{12} \mathrm{H}_{30} \mathrm{~N}_{5} \mathrm{PrO}_{15}$ (found values in parentheses): C 23.05 (22.71), H 4.85 (4.97), N 11.20 (11.27)\%. Characteristic IR bands $\left(\mathrm{KBr}^{\mathrm{c}} \mathrm{cm}^{-1}\right)$ : $\sim 3400 \mathrm{sb}, 3230 \mathrm{~m}, 2940 \mathrm{~m}, 1643 \mathrm{~m}, 1473 \mathrm{~m}, 1010 \mathrm{~m}, 830 \mathrm{w}$.

\subsection{Single-Crystal and Powder X-ray Crystallography}

Suitable crystals of $\mathbf{1} \cdot 2 \mathrm{MeOH}, \mathbf{2} \cdot 2 \mathrm{MeOH}, \mathbf{4} \cdot 2 \mathrm{MeOH}$ and $\mathbf{6}$ had dimensions $0.12 \times 0.18 \times 0.36 \mathrm{~mm}$, $0.10 \times 0.17 \times 0.20 \mathrm{~mm}, 0.10 \times 0.26 \times 0.44 \mathrm{~mm}$ and $0.10 \times 0.16 \times 0.39 \mathrm{~mm}$, respectively. The crystals were taken from the mother liquor and immediately cooled to $-113{ }^{\circ} \mathrm{C}(\mathbf{1} \cdot 2 \mathrm{MeOH}$, $4 \cdot 2 \mathrm{MeOH}, 6)$ or to $-43{ }^{\circ} \mathrm{C}(2 \cdot 2 \mathrm{MeOH})$. Diffraction data were collected on a Rigaku (Tokyo, Japan) R-AXIS SPIDER Image Plate diffractometer using graphite-monochromated Mo K $\alpha$ radiation. Data collection ( $\omega$-scans) and processing (cell refinement, data reduction and Empirical absorption correction) were performed using the CrystalClear program package [55]. Important crystallographic data are listed in Table 1. The structures were solved by direct methods using SHELXS-97 [56] and refined by full-matrix least-squares techniques on $F^{2}$ with SHELXL-2014/6 [57]. Further experimental crystallographic details for $1 \cdot 2 \mathrm{MeOH}: 2 \theta_{\max }=54.0^{\circ}, 262$ parameters refined, $(\Delta / \sigma)_{\max }=0.002$, $(\Delta \varrho)_{\max } /(\Delta \varrho)_{\min }=0.59 /-0.44 \mathrm{e}^{-3}$. Further experimental crystallographic details for $2 \cdot 2 \mathrm{MeOH}: 2 \theta_{\max }$

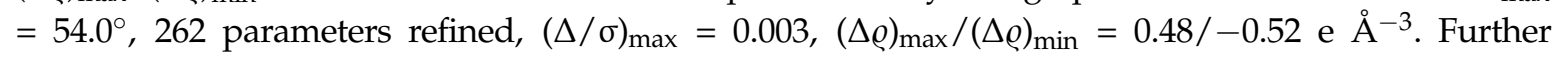
experimental crystallographic details for $4 \cdot 2 \mathrm{MeOH}: 2 \theta_{\max }=54.0^{\circ}, 262$ parameters refined, $(\Delta / \sigma)_{\max }=0.002$, $(\Delta \varrho)_{\max } /(\Delta \varrho)_{\min }=0.55 /-0.54 \mathrm{e} \AA^{-3}$. Further experimental crystallographic details for 6: $2 \theta_{\max }=54.0^{\circ}$, 203 parameters refined, $(\Delta / \sigma)_{\max }=0.055,(\Delta \varrho)_{\max } /(\Delta \varrho)_{\min }=0.46 /-0.28$ e $\AA^{-3}$. In the structure of 6 , the methylene groups defined by the $\mathrm{C} 1$ and $\mathrm{C} 2$ atoms present disorder at two sites with 0.8 and 0.2 occupancies. All $\mathrm{H}$ atoms, except those of the disordered part in 6 , were located by difference maps and were refined isotropically. All non-H atoms were refined anisotropically. Plots of the structures were drawn using the Diamond 3 program package [58]. The X-ray crystallographic data 
for the complexes in CIF formats have been deposited with CCDC (reference numbers CCDC 1522194, 1522195, 1522193 and 1522196 for $\mathbf{1} \cdot 2 \mathrm{MeOH}, \mathbf{2} \cdot 2 \mathrm{MeOH}, \mathbf{4} \cdot 2 \mathrm{MeOH}$ and $\mathbf{6}$, respectively). They can be obtained free of charge at http:/ / www.ccdc.cam.ac.uk//conts/retrieving.html, or from the Cambridge Crystallographic Data Centre, 12 Union Road, Cambridge CB2 1EZ, UK: Fax: +44-1223-336033; or e-mail: deposit@ccdc.cam.ac.uk. Powder X-ray diffraction patterns were collected on a Siemens D500 diffractometer (supplier, Zug, Switzerland) using $\mathrm{Cu} \mathrm{K} \alpha$ radiation.

\section{Conclusions and Perspectives}

In this work, we have shown that the monoanion of triethanolamine can act as a bridging ligand forming dinuclear lanthanide(III) complexes of the general formula $\left[\mathrm{Ln}_{2}\left(\mathrm{NO}_{3}\right)_{4}\left(\mathrm{teaH}_{2}\right)_{2}\right]$. Five members of this family ( $\mathrm{Ln}=\mathrm{Pr}, \mathrm{Gd}, \mathrm{Tb}, \mathrm{Dy}, \mathrm{Ho}$ ) have been fully characterized. Use of excess of the ligand leads to mononuclear $\left.\left[\mathrm{Ln}\left(\mathrm{NO}_{3}\right)(\text { teaH })_{2}\right)_{2}\right]\left(\mathrm{NO}_{3}\right)_{2}$ complexes with the early lanthanide(III) ions in which the ligand is neutral. Complexes 1-5 are the only dinuclear $\mathrm{Ln}^{\mathrm{III}}$ complexes that possess a form of triethanolamine as the only organic ligand. Magnetic studies have shown that the $\mathrm{Gd}^{\mathrm{III}} 2$ complex is characterized by weak to moderate intramolecular, antiferromagnetic exchange interaction; this is most probably the case for the $\mathrm{Tb}^{\mathrm{III}}{ }_{2}$, $\mathrm{Dy}^{\mathrm{III}}{ }_{2}$ and $\mathrm{Ho}^{\mathrm{III}}{ }_{2}$ members of the family. The dinuclear complexes with the anisotropic $\mathrm{Ln}^{\mathrm{III}}$ atoms ( $\mathrm{Ln}=\mathrm{Tb}$, Dy, Ho) do not exhibit SMM behavior; for the Dy III 2 compound this has been rationalized by determining the metal ions' magnetic anisotropy axes the direction of which forces the oblate electron density of Dy ${ }^{\mathrm{III}}$ to be almost parallel to the easy magnetization axis.

We are currently investigating the possibility to prepare $\mathrm{Ln}^{\mathrm{III}}$ complexes with the triply deprotonated form of triethanolamine, i.e., tea $^{3-}$, as ligand; such compounds are not known to date (Table 4) and it is possible that tea ${ }^{3-}$ can stabilize high-nuclearity $\mathrm{Ln}^{\mathrm{III}}$ compounds with interesting magnetic properties. Preliminary studies seem to confirm our expectations. As far as future perspectives are concerned, $\mathrm{Ln}^{\mathrm{III}} / \mathrm{RCO}_{2}{ }^{-} /$teaH ${ }_{2}{ }^{-}$compounds have never been reported and it is currently not known if these complexes are isostructural with 1-5 or the better (compared with the nitrate ion) bridging ability of simple carboxylates can lead to products with other structural types and nuclearities.

Supplementary Materials: The following are available online at http://www.mdpi.com/2312-7481/3/1/5/s1, Figure S1: X-ray powder diffraction patterns of complexes 3, 2 and 4. Figure S2: The IR spectrum $\left(\mathrm{KBr}_{\mathrm{cm}} \mathrm{cm}^{-1}\right)$ of complex 3. Figure S3: The IR spectrum (liquid between CsI disks, $\mathrm{cm}^{-1}$ ) of the free teaH $\mathrm{H}_{3}$ ligand. Figure S4: Partially labeled plot of the molecule $\left[\mathrm{Pr}_{2}\left(\mathrm{NO}_{3}\right)_{4}(\mathrm{teaH})_{2}\right)_{2}$ that is present in the structure of $1 \cdot 2 \mathrm{MeOH}$. Figure S5: Partially labeled plot of the molecule $\left[\mathrm{Gd}_{2}\left(\mathrm{NO}_{3}\right)_{4}\left(\mathrm{teaH}_{2}\right)_{2}\right]$ that is present in the structure of 2.2MeOH. Figure S6: The spherical capped square antiprismatic coordination geometry of Dy1 in the structure of 4.2MeOH. Figure S7: The Johnson tricapped trigonal prismatic coordination geometry of Gd1 in the structure of 2.2MeOH. Figure S8: The spherical-relaxed capped cubic coordination geometry of $\operatorname{Pr} 1$ in the structure of 1.2MeOH. Table S1: Continuous Shape Measures (CShM) values for the potential coordination polyhedra of Dy1/Dy1' in the structure of complex $\left[\mathrm{Dy}_{2}\left(\mathrm{NO}_{3}\right)_{4}\left(\mathrm{teaH}_{2}\right)_{2}\right] \cdot 2 \mathrm{MeOH}(4 \cdot 2 \mathrm{MeOH})$. Table S2: Continuous Shape Measures (CShM) values for the potential coordination polyhedra of $\mathrm{Gd} 1 / \mathrm{Gd}^{\prime}$ in the structure of complex $\left[\mathrm{Gd}_{2}\left(\mathrm{NO}_{3}\right)_{4}\left(\mathrm{teaH}_{2}\right)_{2}\right] \cdot 2 \mathrm{MeOH}(\mathbf{2} \cdot 2 \mathrm{MeOH})$. Table S3: Continuous Shape Measures (CShM) values for the potential coordination polyhedra of $\operatorname{Pr} 1 / \operatorname{Pr} 1^{\prime}$ in the structure of complex $\left[\operatorname{Pr}_{2}\left(\mathrm{NO}_{3}\right)_{4}\left(\mathrm{teaH}_{2}\right)_{2}\right] \cdot 2 \mathrm{MeOH}(\mathbf{1} \cdot 2 \mathrm{MeOH})$. Table S4: Continuous Shape Measures (CShM) values for the potential coordination polyhedra of $\operatorname{Pr} 1$ in the structure of $\left.\left[\mathrm{Pr}\left(\mathrm{NO}_{3}\right)(\mathrm{teaH})_{2}\right)_{2}\right]\left(\mathrm{NO}_{3}\right)_{2}(6)$. Table S5: $\mathrm{H}$ bonds in the crystal structure of complex $\left[\mathrm{Dy}_{2}\left(\mathrm{NO}_{3}\right)_{4}\left(\mathrm{teaH}_{2}\right)_{2}\right] \cdot 2 \mathrm{MeOH}$ (4.2MeOH). Table S6: $\mathrm{H}$ bonds in the crystal structure of complex $\left[\operatorname{Pr}\left(\mathrm{NO}_{3}\right)\left(\mathrm{teaH}_{3}\right)_{2}\right]\left(\mathrm{NO}_{3}\right)_{2}(\mathbf{6})$.

Acknowledgments: Albert Escuer and Julia Mayans thank the Ministeria de Economía y Competitividad, Project CTQ2015-63614-P for funding. Spyros P. Perlepes thanks the COST Action: CA15128-Molecular Spintronics (MOLSPIN) for encouraging his group activities in Patras.

Author Contributions: Ioannis Mylonas-Margaritis and Stavroula-Melina Sakellakou conducted the syntheses, crystallization and conventional characterization of the complexes; the former also contributed to the interpretation of the results. Catherine P. Raptopoulou and Vassilis Psycharis collected crystallographic data, solved the structures and performed structures refinement; the latter also studied the supramolecular features of the crystal structures and wrote the relevant part of the paper. Julia Mayans and Albert Escuer performed the magnetic measurements, interpreted the results and calculated the magnetic anisotropy axes of the Dy ${ }^{\mathrm{III}}$ centers in complex $4 \cdot 2 \mathrm{MeOH}$; the latter also wrote the relevant part of the paper. Spyros P. Perlepes coordinated the research, contributed to the interpretation of the results and wrote parts of the paper. 
Conflicts of Interest: The authors declare no conflict of interest.

\section{References}

1. Luzon, J.; Sessoli, R. Lanthanides in molecular magnetism: So fascinating, so challenging. Dalton Trans. 2012, 41, 13556-13567. [CrossRef] [PubMed]

2. Benelli, C.; Gatteschi, D. Magnetism of Lanthanides in Molecular Materials with Transition-Metal Ions and Organic Radicals. Chem. Rev. 2002, 102, 2369-2387. [CrossRef] [PubMed]

3. Milios, C.J.; Winpenny, R.E.P. Cluster-Based Single-Molecule Magnets. Struct. Bond. 2015, 164, 1-109.

4. For a review on Mn SMMs, see: Bagai, R.; Christou, G. The Drosophila of single-molecule magnetism: $\left[\mathrm{Mn}_{12} \mathrm{O}_{12}\left(\mathrm{O}_{2} \mathrm{CR}\right)_{16}\left(\mathrm{H}_{2} \mathrm{O}\right)_{4}\right]$. Chem. Soc. Rev. 2009, 38, 1011-1026. [CrossRef] [PubMed]

5. Ishikawa, N.; Sugita, M.; Ishikawa, T.; Koshihara, S.-Y.; Kaizu, Y. Lanthanide Double-Decker Complexes Functioning as Magnets at the Single-Molecular Level. J. Am. Chem. Soc. 2003, 125, 8694-8695. [CrossRef] [PubMed]

6. For an excellent and comprehensive review, see: Woodruff, D.N.; Winpenny, R.E.P.; Layfield, R.A. Lanthanide Single-Molecule Magnets. Chem. Rev. 2013, 113, 5110-5138. [CrossRef] [PubMed]

7. Liddle, S.T.; van Slageren, J. Improving f-element single molecule magnets. Chem. Soc. Rev. 2015, 44, 6655-6669. [CrossRef] [PubMed]

8. Li, K.; Zhang, X.; Meng, X.; Shi, W.; Cheng, P.; Powell, A.K. Constraining the coordination geometries of lanthanide centers and magnetic building blocks in frameworks: A new strategy for molecular nanomagnets. Chem. Soc. Rev. 2016, 45, 2423-2439. [CrossRef] [PubMed]

9. Tang, J.; Zhang, P. Polynuclear lanthanide Single Molecule Magnets. In Lanthanides and Actinides in Molecular Magnetism, 1st ed.; Layfields, R.A., Murugesu, M., Eds.; Wiley-VCH: Berlin, Germany, 2015; pp. 61-88.

10. Habib, E.; Murugesu, M. Lessons learned from dinuclear lanthanide nano-magnets. Chem. Soc. Rev. 2013, 42, 3278-3288. [CrossRef] [PubMed]

11. Xue, S.; Guo, Y.-N.; Ungur, L.; Tang, J.; Chibotaru, L. Tuning the Magnetic Interactions and Relaxation Dynamics of Dy $\mathrm{y}_{2}$ Single-Molecule Magnets. Chem. Eur. J. 2015, 21, 14099-14106. [CrossRef] [PubMed]

12. Jiang, Y.; Brunet, G.; Holmberg, R.J.; Habib, F.; Karobkov, I.; Murugesu, M. Terminal solvent effects on the anisotropy barriers of Dy2 systems. Dalton Trans. 2016, 45, 16709-16715. [CrossRef] [PubMed]

13. Xiong, J.; Ding, H.-Y.; Meng, Y.-S.; Gao, C.; Zhang, X.-J.; Meng, Z.-S.; Zhang, Y.-Q.; Shi, W.; Wang, B.-W.; Gao, S. Hydroxide-bridged five-coordinate Dy ${ }^{\mathrm{III}}$ single-molecule magnet exhibiting the record thermal relaxation barrier of magnetization among lanthanide-only dimmers. Chem. Sci. 2016. [CrossRef]

14. Rinehart, J.D.; Fang, M.; Evans, W.J.; Long, J.R. Strong exchange and magnetic blocking in $\mathrm{N}_{2}{ }^{3-}$-radical-bridged lanthanide complexes. Nat. Chem. 2011, 3, 538-542. [CrossRef] [PubMed]

15. Guo, Y.-N.; Xu, G.-F.; Wernsdorfer, W.; Ungur, L.; Guo, Y.; Tang, J.; Zhang, H.-J.; Chibotaru, L.F. Strong Axiality and Ising Exchange Interaction Suppress Zero-Field Tunneling of Magnetization of an Asymmetric Dy 2 Single-Molecule Magnet. J. Am. Chem. Soc. 2011, 133, 11948-11951. [CrossRef] [PubMed]

16. Gao, F.; Li, Y.-Y.; Liu, C.-M.; Li, Y.-Z.; Zuo, J.-L. A sandwich-type triple-decker lanthanide complex with mixed phthalocyanine and Schiff base ligands. Dalton Trans. 2013, 42, 11043-11046. [CrossRef] [PubMed]

17. Yi, X.; Bernot, K.; Cador, O.; Luzon, J.; Calvez, G.; Daiguebonne, C.; Guillou, O. Influence of ferromagnetic connection of Ising-type Dy ${ }^{\mathrm{III}}$-based single ion magnets on their magnetic slow relaxation. Dalton Trans. 2013, 42, 6728-6731. [CrossRef] [PubMed]

18. Nematirad, M.; Gee, W.J.; Langley, S.K.; Chilton, N.F.; Moubaraki, B.; Murray, K.S.; Batten, S.R. Single molecule magnetism in a $\mu$-phenolato dinuclear motif ligated by heptadentate Schiff base ligands. Dalton Trans. 2012, 41, 13711-13715. [CrossRef] [PubMed]

19. Xu, G.-F.; Wang, Q.-L.; Gamez, P.; Ma, Y.; Clérac, R.; Tang, J.; Yan, S.-P.; Cheng, P.; Liao, D.-Z. A promising new route towards single-molecule magnets based on the oxalate ligand. Chem. Commun. 2010, 46, 1506-1508. [CrossRef] [PubMed]

20. Roy, L.E.; Hughbanks, T. Magnetic Coupling in Dinuclear Gd Complexes. J. Am. Chem. Soc. 2006, 128, 568-575. [CrossRef] [PubMed]

21. Luis, F.; Repollés, A.; Martínez-Pérez, M.J.; Aguilà, D.; Roubeau, O.; Zueco, D.; Alonso, P.J.; Evangelisti, M.; Camón, A.; Sesé, J.; et al. Molecular Prototypes for Spin-Based CNOT and SWAP Quantum Gates. Phys. Rev. Lett. 2011, 107, 117203-1-117203-5. [CrossRef] [PubMed] 
22. Pedersen, K.S.; Ariciu, A.-M.; McAdams, S.; Weihe, H.; Bendix, J.; Tuna, F.; Piligkos, S. Towards Molecular 4f Single-Ion Magnet Qubits. J. Am. Chem. Soc. 2016, 138, 5801-5804. [CrossRef] [PubMed]

23. For example, see: Anastasiadis, N.C.; Mylonas-Margaritis, I.; Psycharis, V.; Raptopoulou, C.P.; Kalofolias, D.A.; Milios, C.J.; Klouras, N.; Perlepes, S.P. Dinuclear, tetrakis(acetato)-bridged lanthanide(III) complexes from the use of 2-acetylpyridine hydrazone. Inorg. Chem. Commun. 2015, 51, 99-102. [CrossRef]

24. Lin, P.-H.; Burchell, T.J.; Clérac, R.; Murugesu, M. Dinuclear Dysprosium(III) Single-Molecule Magnets with a large Anisotropic Barrier. Angew. Chem. Int. Ed. 2008, 47, 8848-8851. [CrossRef] [PubMed]

25. Anastasiadis, N.C.; Kalofolias, D.A.; Philippidis, A.; Tzani, S.; Raptopoulou, C.P.; Psycharis, V.; Milios, C.J.; Escuer, A.; Perlepes, S.P. A family of dinuclear lanthanide(III) complexes from the use of a tridentate Schiff base. Dalton Trans. 2015, 44, 10200-10209. [CrossRef] [PubMed]

26. Anastasiadis, N.C.; Granadeiro, C.M.; Klouras, N.; Cunha-Silva, L.; Raptopoulou, C.P.; Psycharis, V.; Bekiari, V.; Balula, S.S.; Escuer, A.; Perlepes, S.P. Dinuclear Lanthanide(III) Complexes by Metal-Ion-Assisted Hydration of Di-2-pyridyl Ketone Azine. Inorg. Chem. 2013, 52, 4145-4147. [CrossRef] [PubMed]

27. Nikolaou, H.; Terzis, A.; Raptopoulou, C.P.; Psycharis, V.; Bekiari, V.; Perlepes, S.P. Unique Dinuclear, Tetrakis (nitrato-O,O' )-Bridged Lanthanide(III) Complexes from the Use of Pyridine-2-Amidoxime: Synthesis, Structural Studies and Spectroscopic Characterization. J. Surf. Interfaces Mater. 2014, 2, 311-318. [CrossRef]

28. Murugesu, M.; Mishra, A.; Wernsdorfer, W.; Abboud, K.A.; Christou, G. Mixed 3d/4d and 3d/4f metal clusters: Tetranuclear Fe ${ }_{2}^{\mathrm{III}}{ }_{2} \mathrm{M}^{\mathrm{III}}\left(\mathrm{M}^{\mathrm{III}}=\mathrm{Ln}, \mathrm{Y}\right.$ and $\mathrm{Mn}^{\mathrm{IV}}{ }_{2} \mathrm{M}^{\mathrm{III}}{ }_{2}(\mathrm{M}=\mathrm{Yb}, \mathrm{Y})$ complexes and the first Fe $/ 4 \mathrm{f}$ single-molecule magnets. Polyhedron 2006, 25, 613-625. [CrossRef]

29. Schray, D.; Abbas, G.; Lan, Y.; Mereacre, V.; Sundt, A.; Dreiser, J.; Waldmann, O.; Kostakis, G.E.; Anson, C.E.; Powell, A.K. Combined Magnetic Susceptibility Measurements and ${ }^{57}$ Fe Mössbauer Spectroscopy on a Ferromagnetic $\left\{\mathrm{Fe}^{\mathrm{III}}{ }_{4} \mathrm{Dy}_{4}\right\}$ Ring. Angew. Chem. Int. Ed. 2010, 49, 5185-5188. [CrossRef] [PubMed]

30. Chilton, N.F.; Langley, S.K.; Moubaraki, B.; Murray, K.S. Synthesis, structural and magnetic studies of an isostructural family of mixed $3 \mathrm{~d} / 4 \mathrm{f}$ tetranuclear 'star' clusters. Chem. Commun. 2010, 46, 7787. [CrossRef] [PubMed]

31. Langley, S.K.; Wielechowski, D.P.; Moubaraki, B.; Abrahams, B.F.; Murray, K.S. Magnetic Exchange Effects in $\left\{\mathrm{Cr}^{\mathrm{III}}{ }_{2} \mathrm{Dy}_{2}{ }_{2}\right\}$ Single Molecule Magnets Containing Alcoholamine Ligands. Aust. J. Chem. 2014, 67, 1581-1587. [CrossRef]

32. Hahn, F.E.; Mohr, J. Synthese und Strukturen von Bis(triethanolamin)lanthanoid-Komplexen. Chem. Ber. 1990, 123, 481-484. [CrossRef]

33. Starynowicz, P. Synthesis and structure of bis(triethanolamine)europium(II) diperchlorate. J. Alloy. Compd. 2001, 323-324, 159-163. [CrossRef]

34. Starynowicz, P.; Gatner, K. An Ytterbium(II) Complex with Triethanolamine. Z. Anorg. Allg. Chem. 2003, 629, 722-726. [CrossRef]

35. Fowkes, A.; Harrison, W.T.A. (Nitrato- $\left.\mathrm{k}^{2} \mathrm{O}, \mathrm{O}^{\prime}\right)$ bis(triethanolamine- $\left.{ }^{4} \mathrm{~N}, \mathrm{O}^{\prime} \mathrm{O}^{\prime}, \mathrm{O}^{\prime \prime}\right)$ lanthanum(III) dinitrate. Acta Crystallogr. Sect. C 2006, 62, m232-m233. [CrossRef] [PubMed]

36. Kumar, R.; Obrai, S.; Jassal, A.K.; Hundai, M.S. Supramolecular architectures of $N, N, N^{\prime}, N^{\prime}$-tetrakis (2-hydroxyethyl)ethylenediamine and tris(2-hydroxyethyl)amine with La(III) picrate. RSC Adv. 2014, 4, 59248-59264. [CrossRef]

37. Langley, S.K.; Moubaraki, B.; Forsyth, G.M.; Gass, I.A.; Murray, K.S. Structure and magnetism of new lanthanide 6-wheel compounds utilizing triethanolamine as a stabilizing ligand. Dalton Trans. 2010, 39, 1705-1708. [CrossRef] [PubMed]

38. Langley, S.K.; Moubaraki, B.; Murray, K.S. Magnetic Properties of Hexanuclear Lanthanide(III) Clusters Incorporating a Central $\mu_{6}$-Carbonate Ligand Derived from Atmospheric $\mathrm{CO}_{2}$ Fixation. Inorg. Chem. 2012, 51, 3947-3949. [CrossRef] [PubMed]

39. Langley, S.K.; Moubaraki, B.; Murray, K.S. Trinuclear, octanuclear and decanuclear dysprosium(III) complexes: Synthesis, structural and magnetic studies. Polyhedron 2013, 64, 255-261. [CrossRef]

40. Zhang, L.; Zhang, P.; Zhao, L.; Lin, S.-Y.; Xue, S.; Tang, J.; Liu, Z. Two Locally Chiral Dysprosium Compounds with Salen-Type Ligands That Show Slow Magnetic Relaxation Behaviour. Eur. J. Inorg. Chem. 2013, 1351-1357. [CrossRef]

41. Naini, A.A.; Young, V.; Verkade, J.G. New complexes of Triethanolamine (TEA): Novel Structural Features of $\left[\mathrm{Y}(\mathrm{TEA})_{2}\right]\left(\mathrm{ClO}_{4}\right)_{3} \cdot 3 \mathrm{C}_{5} \mathrm{H}_{5} \mathrm{~N}$ and $\left[\mathrm{Cd}(\mathrm{TEA})_{2}\right]\left(\mathrm{NO}_{3}\right)_{2}$. Polyhedron 1995, 14, 393-400. [CrossRef] 
42. Tsantis, S.T.; Zagoraiou, E.; Savvidou, A.; Raptopoulou, C.P.; Psycharis, V.; Szyrwiel, L.; Holyńska, M.; Perlepes, S.P. Binding of oxime group to uranyl ion. Dalton Trans. 2016, 45, 9307-9319. [CrossRef] [PubMed]

43. Kitos, A.A.; Efthymiou, C.G.; Manos, M.J.; Tasiopoulos, A.J.; Nastopoulos, V.; Escuer, A.; Perlepes, S.P. Interesting Copper(II)-assisted transformations of 2-acetylpyridine and 2-benzoylpyridine. Dalton Trans. 2016, 45, 1063-1077. [CrossRef] [PubMed]

44. Hao, J.-M.; Yu, B.-Y.; Hecke, V.K.; Cui, G.-H. A series of $\mathrm{d}^{10}$ metal coordination polymers based on a flexible bis(2-methylbenzimidazole) ligand and different carboxylates: Synthesis, structures, photoluminescence and catalytic properties. CrystEngComm 2015, 17, 2279-2293. [CrossRef]

45. Cui, G.-H.; He, C.-H.; Jiao, C.-H.; Geng, J.-C.; Blatov, V.A. Two metal-organic frameworks with unique high-connected binodal network topologies: Synthesis, structures, and catalytic properties. CrystEngComm 2012, 14, 4210-4216. [CrossRef]

46. For example, see: Polyzou, C.D.; Nikolaou, H.; Papatriantafyllopoulou, C.; Psycharis, V.; Terzis, A.; Raptopoulou, C.P.; Escuer, A.; Perlepes, S.P. Employment of methyl 2-pyridyl ketone oxime in 3d/4f-metal chemistry: Dinuclear nickel(II)/lanthanide(III) species and complexes containing the metals in separate ions. Dalton Trans. 2012, 41, 13755-13764. [CrossRef] [PubMed]

47. Llunell, M.; Casanova, D.; Girera, J.; Alemany, P.; Alvarez, S. SHAPE, Continuous Shape Measures Calculation, version 2.0; Universitat de Barcelona: Barcelona, Spain, 2010.

48. Ruiz-Martínez, A.; Casanova, D.; Alvarez, S. Polyhedral Structures with an Odd Number of Vertices: Nine-Coordinate Metal Compounds. Chem. Eur. J. 2008, 14, 1291-1303. [CrossRef] [PubMed]

49. Kepert, D.L. Inorganic Stereochemistry; Springer: Berlin, Germany, 1982; pp. 179-187.

50. Long, J.; Habib, F.; Lin, P.-H.; Korobkov, I.; Enright, G.; Ungur, L.; Wernsdorfer, W.; Chibotaru, L.F.; Murugesu, M. Single-Molecule Magnet Behaviour for an Antiferromagnetically Superexchange-Coupled Dinuclear Dysprosium(III) Complex. J. Am. Chem. Soc. 2011, 133, 5319. [CrossRef] [PubMed]

51. Rinehart, J.D.; Long, J.R. Exploiting single-ion anisotropy in the design of f-element single-molecule magnets. Chem. Sci. 2011, 2, 2078-2085. [CrossRef]

52. Chilton, N.F.; Collison, D.; McInnes, E.J.I.; Winpenny, R.E.P.; Soncini, A. An electrostatic model for the determination of magnetic anisotropy in dysprosium complexes. Nat. Commun. 2013, 4, 2551-2557. [CrossRef] [PubMed]

53. Kettle, S.F.A. Physical Inorganic Chemistry-A Coordination Chemistry Approach; Oxford University Press: Oxford, UK, 1998; pp. 462-465.

54. Chilton, N.F.; Anderson, R.P.; Turner, L.D.; Soncini, A.; Murray, K.S. PHI: A Powerful New Program for the Analysis of Polynuclear d- and f-block Complexes. J. Comput. Chem. 2013, 34, 1164-1175. [CrossRef] [PubMed]

55. CrystalClear, version 1.40; Rigaku/MSC: The Woodlands, TX, USA, 2005.

56. Sheldrick, G.M. SHELXS 97, Program for Structure Solution; University of Göttingen: Göttingen, Germany, 1997.

57. Sheldrick, G.M. Crystal structure refinement with SHELXL. Acta Crystallogr. Sect. C. 2005, 71, 3-8.

58. DIAMOND, Crystal and Molecular Structure Visualization, version 3.1; Crystal Impact: Bonn, Germany.

(C) 2017 by the authors; licensee MDPI, Basel, Switzerland. This article is an open access article distributed under the terms and conditions of the Creative Commons Attribution (CC BY) license (http:/ / creativecommons.org/licenses/by/4.0/). 